University of South Florida

DIGITAL COMMONS

Digital Commons @ University of

@ UNIVERSITY OF SOUTH FLORIDA

South Florida

10-15-1999

\title{
West Florida Continental Shelf Response to Upwelling Favorable Wind Forcing 2. Dynamics
}

\section{Zhenjiang Li}

University of South Florida

Robert H. Weisberg

University of South Florida, weisberg@marine.usf.edu

Follow this and additional works at: https://digitalcommons.usf.edu/msc_facpub

Part of the Marine Biology Commons

\section{Scholar Commons Citation}

$\mathrm{Li}$, Zhenjiang and Weisberg, Robert H., "West Florida Continental Shelf Response to Upwelling Favorable Wind Forcing 2. Dynamics" (1999). Marine Science Faculty Publications. 123.

https://digitalcommons.usf.edu/msc_facpub/123

This Article is brought to you for free and open access by the College of Marine Science at Digital Commons @ University of South Florida. It has been accepted for inclusion in Marine Science Faculty Publications by an authorized administrator of Digital Commons @ University of South Florida. For more information, please contact digitalcommons@usf.edu. 


\title{
West Florida continental shelf response to upwelling favorable wind forcing
}

\section{Dynamics}

\author{
Zhenjiang $\mathrm{Li}$ and Robert $\mathrm{H}$. Weisberg \\ Department of Marine Science, University of South Florida, St. Petersburg
}

\begin{abstract}
Dynamics analyses are presented for the west Florida continental shelf response to upwelling favorable, alongshore or offshore winds using a three-dimensional, time-dependent, primitive equation model. These analyses complement the kinematics analyses of $L i$ and Weisberg [1999]. Results are provided on four topics: (1) the response evolutions to quasi steady states, (2) the across-shelf distributions of the vertically integrated alongshore and across-shelf momentum balances, (3) the three-dimensional structures of the terms composing the momentum balance closures, and (4) the model sensitivity to vertical friction parameterization. The response evolution starts with a local wind-driven acceleration, and it transitions over the inner shelf into a primary balance between the pressure gradient, Coriolis, and vertical friction terms. Thus the inner shelf spin-up takes a classical Ekman-geostrophic route. The middle shelf takes longer because it also depends on coastal boundary effects, notably the partial closure of the domain in the south by the Florida Keys. The outer shelf never achieves a steady state because of topographic wave effects. Coastline and isobath geometries result in fully threedimensional flow fields. Thus a two-dimensional model that ignores alongshore variations cannot account for the results obtained. The inner shelf is the transition region between Ekman and Ekman-geostrophic balances where the surface slope results from mass adjustments through overlapping surface and bottom Ekman layers. Across the inner shelf the vertically integrated momentum balance shows a gradual trade-off between the Coriolis, pressure gradient, and bottom friction terms, and with the inner shelf frictionally determined its scale is sensitive to vertical friction parameterization.
\end{abstract}

\section{Introduction}

The west Florida continental shelf (WFS) is a gently sloping region of width approximately equal to the State of Florida. Bounded by the Florida Keys in the south and the Florida Panhandle coast in the north, the WFS accounts for about one quarter of the Gulf of Mexico circumference. The large width (that provides separation between the inner, middle, and outer shelf regions), the coastline and isobath geometries (that lead to fully three-dimensional flow fields), and the presence at times of the Loop Current near the shelf break all combine to make the WFS an excellent continental shelf laboratory. Motivated by these factors, along with pragmatic societal concerns such as red-tide outbreaks, a coordinated program of study consisting of in situ measurements and numerical circulation models is in progress. Building upon earlier WFS model studies, either vertically averaged with realistic geometry [Hsueh et $a l ., 1982$ ] or three-dimensional with unrealistic geometry [Cooper, 1987], our initial model objective was to apply a fully three-dimensional, primitive equation model for studying upwelling responses to typical synoptic-scale weather systems. We selected the public domain Princeton Ocean Model (POM) of Blumberg and Mellor [1987] for this purpose by virtue of its free surface and turbulence closure capabilities. In order to provide a context for viewing more complicated forc-

Copyright 1999 by the American Geophysical Union.

Paper number 1999JC900205.

0148-0227/99/1999JC900205\$09.00 ing functions, we began with initial value problems forced from a state of rest by uniform wind stresses directed either alongshore or offshore relative to Florida's west coast. Li and Weisberg [1999], hereafter referred to as Part 1, describe these experiments and the ensuing flow field kinematics. The present paper adds the dynamical descriptions for these flow fields. This paper may be read independently of Part 1 ; however, the flow fields are not duplicated nor are discussions of many pertinent papers.

Baseline experiments using default model parameters are described, and these are followed by experiments designed to test the sensitivity of the model to the default parameters. This is important since vertical friction plays a significant role in the wind-forced response of the shelf. For both the alongshore and offshore forcing cases we begin by describing the time evolution of the terms in the vertically averaged momentum balances in both the alongshore and the across-shelf directions. This is followed by a description of the across-shelf variations of these vertically averaged momentum terms in the quasi steady state. These descriptions allow us to define inner, middle, and outer shelf regions on dynamical grounds and to discuss the rapid spin-up of the model to quasi steady state. Consistent with Mitchum and Clarke [1986] and Lentz [1995], the inner shelf is essentially the region in which this Ekmangeostrophic spin-up process takes place. Following the vertically averaged momentum balance discussions, we explore the three-dimensional distribution of the quasi steady state momentum terms. Owing to the coastline and isobath geometries the flow fields and their associated momentum balances are 

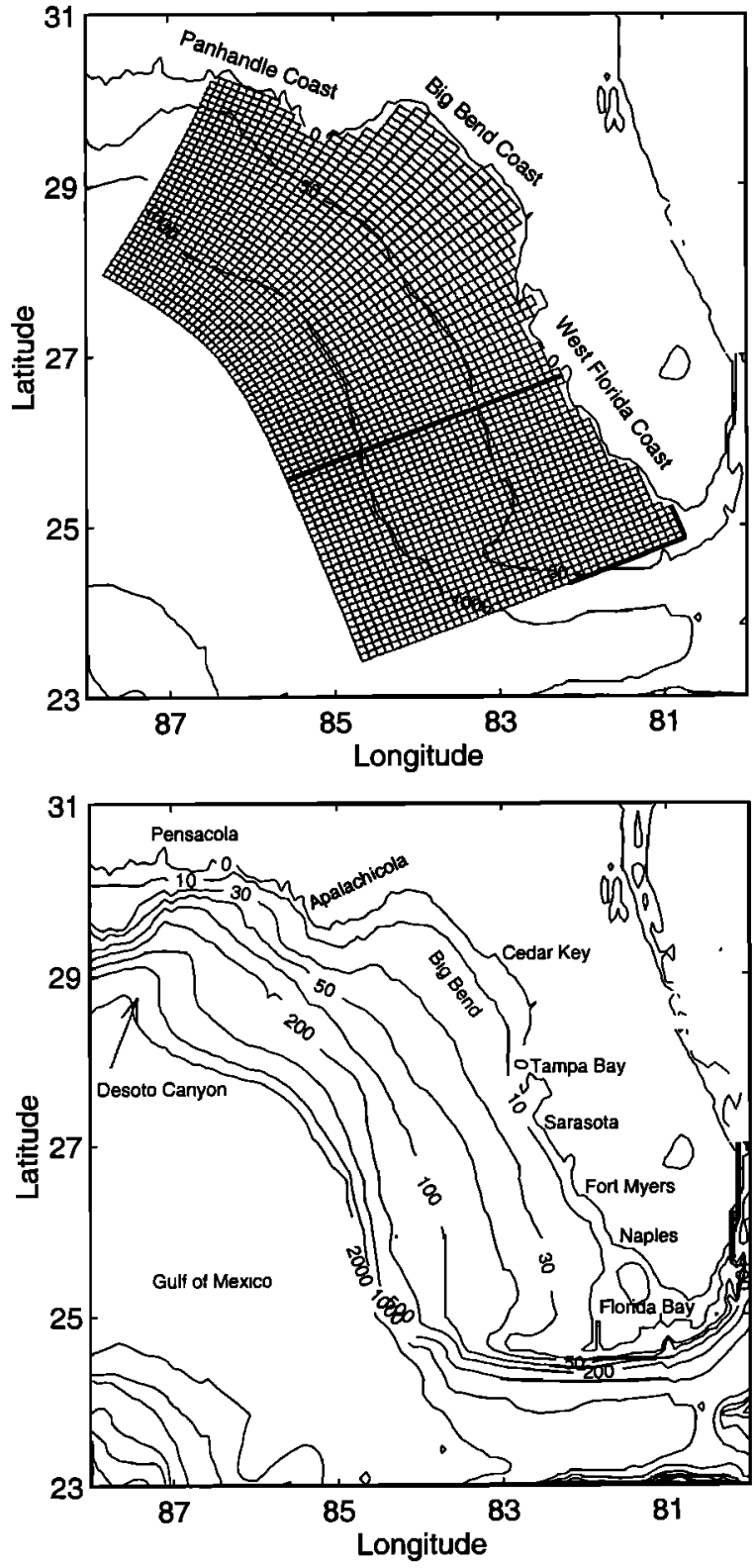

Figure 1. (top) The model domain with an average grid size of approximately $9 \mathrm{~km}$ and (bottom) the west Florida shelf bathymetry. The bold line off Sarasota denotes the across-shelf section discussed in the text, and the bold line to the south denotes the partial closure of the southern boundary by the Florida Keys.

fully three-dimensional. For this reason, along with alongshore directed winds, we find that offshore directed winds are also effective at driving alongshore currents, and this finding is in contrast with the case of strictly two-dimensional flows [e.g., Csanady, 1976].

Similar to findings of other continental shelf modeling studies [e.g., Allen et al., 1995; Dickey and Van Leer, 1984; Lentz, 1995; Weatherly and Martin, 1978], the model WFS response is sensitive to the vertical eddy viscosity specification. We therefore explore the three-dimensional structure of the turbulent eddy coefficient calculated by the POM's default MellorYamada level 2.5 turbulence closure submodel [Mellor and Yamada, 1982], and we compare model results when the de- fault turbulence closure is replaced with constant eddy coefficients specified over 3 orders of magnitude. These experiments provide further insight into the nature of the inner shelf.

This paper is arranged as follows. Section 2 describes the momentum structures from the baseline upwelling favorable to alongshore and offshore wind experiments. The turbulence features from the Mellor-Yamada turbulence closure submodel are presented in section 3. The results from the sensitivity experiments are given in section 4 . Section 5 then provides a summary and discussion.

\section{Momentum Structures From the Basic Experiments}

Two benchmark runs are considered, one for alongshore winds and the other for offshore winds. In both cases the wind stresses are spatially uniform with magnitudes of $1 \mathrm{dyn} \mathrm{cm}^{-2}$. For the alongshore and offshore winds the orientations (with respect to true north) are $150^{\circ}$ and $240^{\circ}$, respectively, so alongshore and offshore are defined relative to the west coast of the Florida Peninsula. The shelf water density is set homogeneously at $1023 \mathrm{~kg} \mathrm{~m}^{-3}$, and each model run starts from a state of rest. Details on the model formulation, the experimental design, and the model response kinematics are provided in Part 1. Figure 1 shows the model domain and the coastline and isobath geometries.

The modeled WFS circulation responses to wind forcing evolve rapidly to quasi steady states. Investigating the momentum balance evolution over different stages of evolution is important for understanding the dynamical regimes that occur on the shelf and for gauging the credibility of the POM against the conceptual expectation for these regimes. We therefore explore the dynamical balances in terms of (1) time series evolution, (2) depth-integrated distributions, and (3) threedimensional structure. For the following presentations all of the momentum terms (except for the time series) are sampled from time series that are averaged over an inertial period to isolate the synoptic-scale features of the flow fields. For discussion purposes the terms "Coriolis," "pressure gradient," "advection," and "local acceleration" have their usual force per unit volume meaning except when used to discuss the depthintegrated momentum structures, in which case they refer to depth-integrated quantities.

\subsection{Southeastward Alongshore Wind Experiment}

The response evolution undergoes three identifiable stages in approaching the quasi steady state. These are evidenced in the Figure 2 depth-integrated momentum terms for both the alongshore and the across-shelf momentum equations evaluated at an inner shelf, $\mathbf{1 5 . 3} \mathrm{m}$ depth site located off Sarasota. The first stage begins with the imposed wind forcing, and it lasts for only a few hours. During this initial stage the wind directly accelerates the water in the alongshore direction with the vertically integrated momentum balance being between the wind stress and the local acceleration. With time the advective acceleration, bottom stress, and alongshore pressure gradient terms build in such a way as to decrease the local acceleration. This more gradual second-stage development proceeds over somewhat less than a day, after which the primary balance in the alongshore direction is between the wind stress and the bottom stress. The third stage which then persists for several days entails a slowly damped oscillation between all of the remaining terms such that the primary momentum balance in 

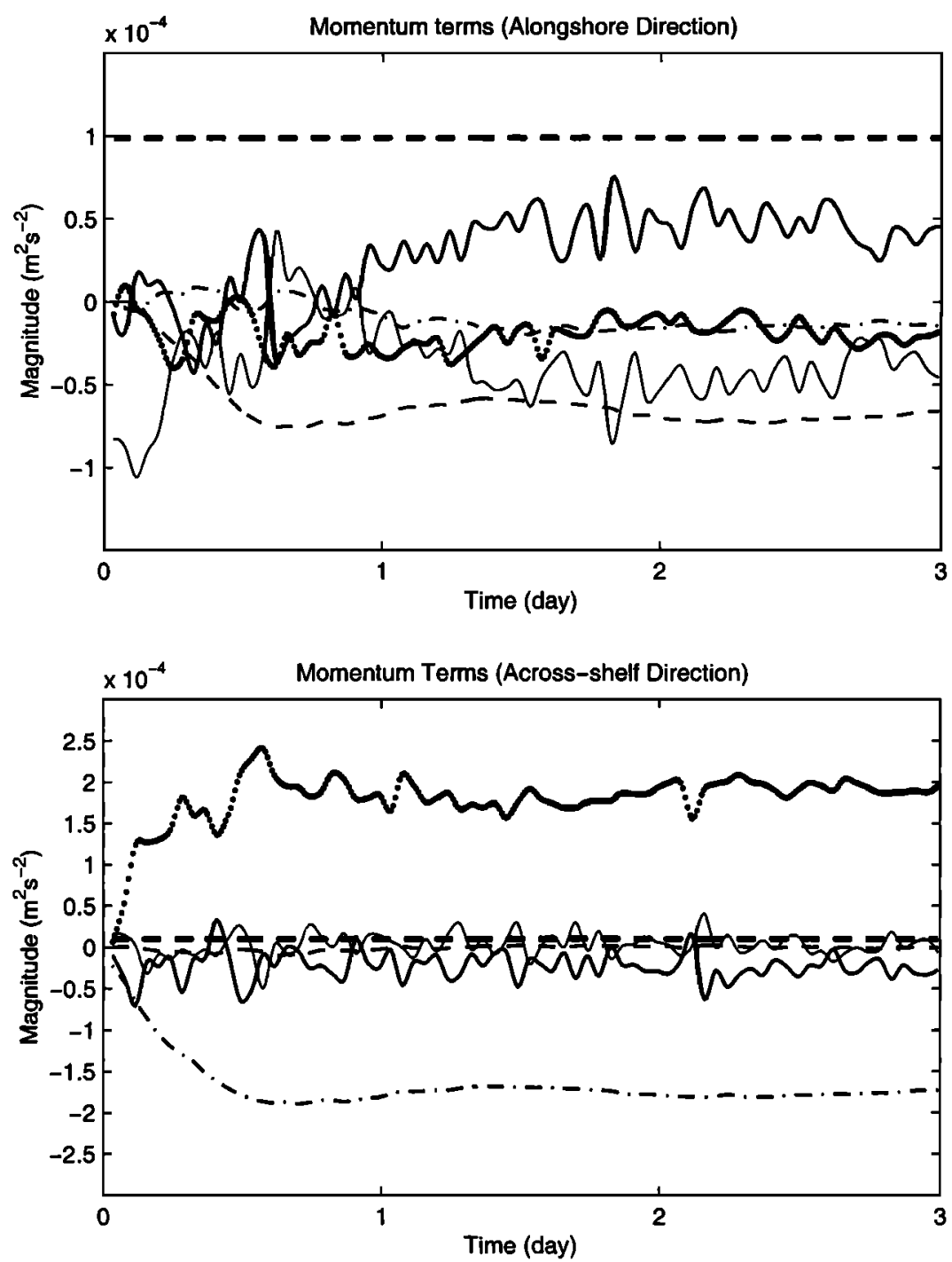

Figure 2. Initial evolution of the depth-integrated momentum terms for both the (top) alongshore and (bottom) across-shelf momentum equations from the southeastward alongshore wind case at a site offshore from Sarasota at $15.3 \mathrm{~m}$ depth. The pressure gradient term is the bold dotted line, the Coriolis term is the dash-dotted line, the wind stress term is the bold dashed line, the bottom stress term is the thin dashed line, the advection term is the bold solid line, and the local acceleration term is the thin solid line.

the alongshore direction remains one of wind stress balancing bottom stress at this location. Note that the local and advective acceleration terms tend to cancel, rendering the material acceleration small throughout this third stage.

The accompanying evolution in the across-shelf direction is similar with the exception of the instantaneous local acceleration. Skipping stage one since there is no applied force in that direction, the stage two response consists of a gradual buildup of the across-shelf pressure gradient coincident with the gradual buildup of the across-shelf Ekman transport farther offshore and its inner shelf divergence due to the coastal boundary. As the alongshore current accelerates, its associated across-shelf Coriolis force increases tending to balance the across-shelf pressure gradient. Thus the bottom stress in the alongshore momentum balance (due to the alongshore current) and the Coriolis force in the across-shelf momentum balance (also due to the alongshore current) covary and play complementary roles in these respective coordinate direction equations. The relatively high frequency variations present in the pressure gradient and acceleration terms (and absent in the Coriolis term) are due to gravity waves.

The evolution of these depth-integrated momentum terms is dependent upon water depth. How the quasi steady state balances vary across the shelf is shown in Figure 3 for the alongshore and the across-shelf momentum equations at a section sampled offshore from Sarasota (Figure 1). For consistency with Part 1 the quasi steady state balances are sampled at day 12. This is not restrictive since the momentum balance patterns, like the flow field kinematics (Part 1), are established quickly.

Consider the alongshore momentum balance first. In deep water (the middle to outer shelf) the alongshore momentum balance is primarily between the wind stress and the Coriolis terms, which is, in essence, an Ekman balance. As the water depth shoals, the Coriolis term is increasingly offset by the bottom friction term because of the alongshore coastal jet. 

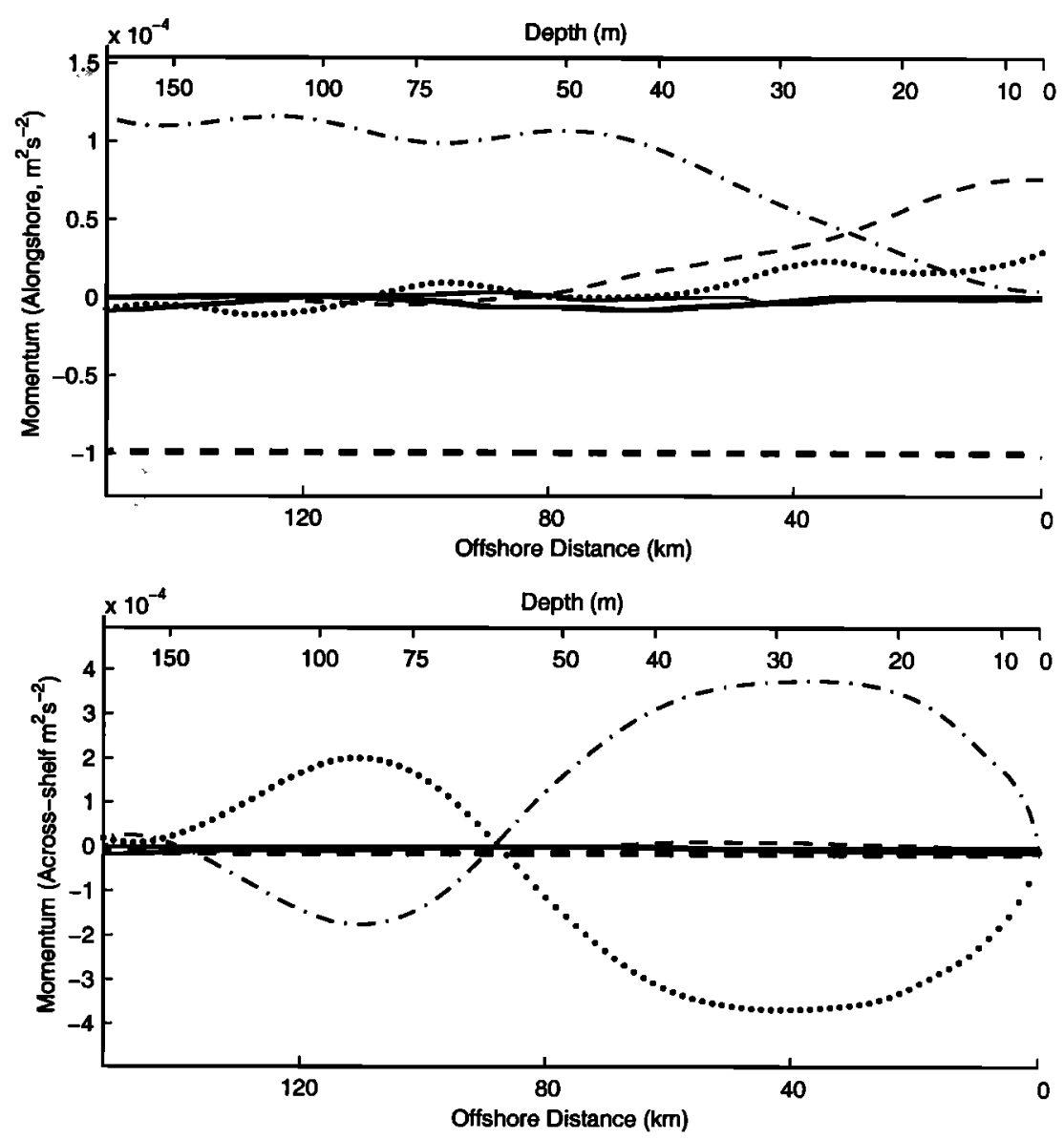

Figure 3. (top) The alongshore and (bottom) the across-shelf depth-integrated momentum terms on day 12 sampled offshore from Sarasota for the southeastward alongshore wind case. The pressure gradient term is the bold dotted line, the Coriolis term is the dash-dotted line, the wind stress term is the bold dashed line, the bottom stress term is the thin dashed line, the advection term is the bold solid line, and the local acceleration term is the thin solid line.

This transition region, within which the surface and bottom Ekman layers interact, defines the inner shelf [Mitchum and Clarke, 1986; Lentz, 1995]. Offshore from Sarasota our POM experimentation suggests that the $50 \mathrm{~m}$ isobath is the approximate demarcation point for the inner shelf, the center of which occurs at about $25 \mathrm{~m}$ depth where the Coriolis and bottom stress terms are of equal magnitude. Only in the shallowest water ( $5 \mathrm{~m}$ minimum depth in the model) does the bottom stress together with the pressure gradient nearly balance the surface stress. Therefore only in the shallowest water does the vertically integrated across-shelf transport approach zero.

The momentum balance in the across-shelf direction is complementary. Here the balance is primarily between the pressure gradient and the Coriolis terms, which is, in essence, a geostrophic balance. Both of these terms are largest at the center of the inner shelf, and this defines the center of the coastal jet which occurs at about the $30 \mathrm{~m}$ isobath. Farther offshore there is a countercurrent (described in Part 1) associated with a reversal in pressure gradient.

In summary, the vertically integrated across-shelf momentum balance is essentially geostrophic independent of water depth. Contrastingly, the vertically integrated alongshore momentum balance is essentially Ekman over the middle to outer shelf. The inner shelf is defined as the transition region through which the bottom Ekman layer (due to the coastal jet) takes on an increasing role with decreasing water depth. While not shown, other across-shelf sections show similar behavior but modulated by bottom slope. In the Big Bend, where the shelf is wider and the slope is more gradual, the inner shelf region extends farther offshore. Contrastingly, in the Panhandle, where the shelf is narrower and the slope is steeper, the

Table 1. Ranges of the Momentum Terms in the AcrossShelf and Alongshore Momentum Equations at the Subsurface Level From the Southeastward Alongshore Wind Forcing Experiment

\begin{tabular}{llllll}
\hline & $\begin{array}{c}\text { Across-Shelf } \\
\text { Momentum } \\
\text { Equation }\end{array}$ & & & $\begin{array}{c}\text { Alongshore } \\
\text { Momentum } \\
\text { Equation }\end{array}$ \\
\cline { 2 - 3 } \cline { 5 - 6 } \multicolumn{1}{c}{ Term } & $\begin{array}{c}\text { Range, } \\
\mathrm{m} \mathrm{s}^{-2}\end{array}$ & Rank & & $\begin{array}{c}\text { Range, } \\
\mathrm{m} \mathrm{s}^{-2}\end{array}$ & Rank \\
\hline Local acceleration & $5.2 \times 10^{-7}$ & 3 & & $3.6 \times 10^{-7}$ & 3 \\
Advective acceleration & $3.9 \times 10^{-6}$ & 2 & & $1.2 \times 10^{-6}$ & 2 \\
Horizontal friction & $4.6 \times 10^{-7}$ & 3 & & $6.3 \times 10^{-7}$ & 3 \\
Coriolis & $4.0 \times 10^{-5}$ & 1 & & $2.8 \times 10^{-5}$ & 1 \\
Pressure gradient & $7.4 \times 10^{-5}$ & 1 & & $7.0 \times 10^{-5}$ & 1 \\
Vertical eddy friction & $4.7 \times 10^{-5}$ & 1 & & $7.2 \times 10^{-5}$ & 1 \\
\hline
\end{tabular}


inner shelf region is confined closer to the shore. The two coordinate direction momentum equations are related in that it is the across-shelf divergence in the surface Ekman layer (that appears in the alongshore momentum equation) that sets up the across-shelf pressure gradient and the associated alongshore coastal jet (that appears in the across-shelf momentum equation). The coastal jet, in turn, produces the bottom Ekman layer stress (that appears in the alongshore momentum equation) that makes up for the decrease in the total across-shelf Ekman layer transports as the water depth decreases.

Missing from the vertically integrated momentum discussion
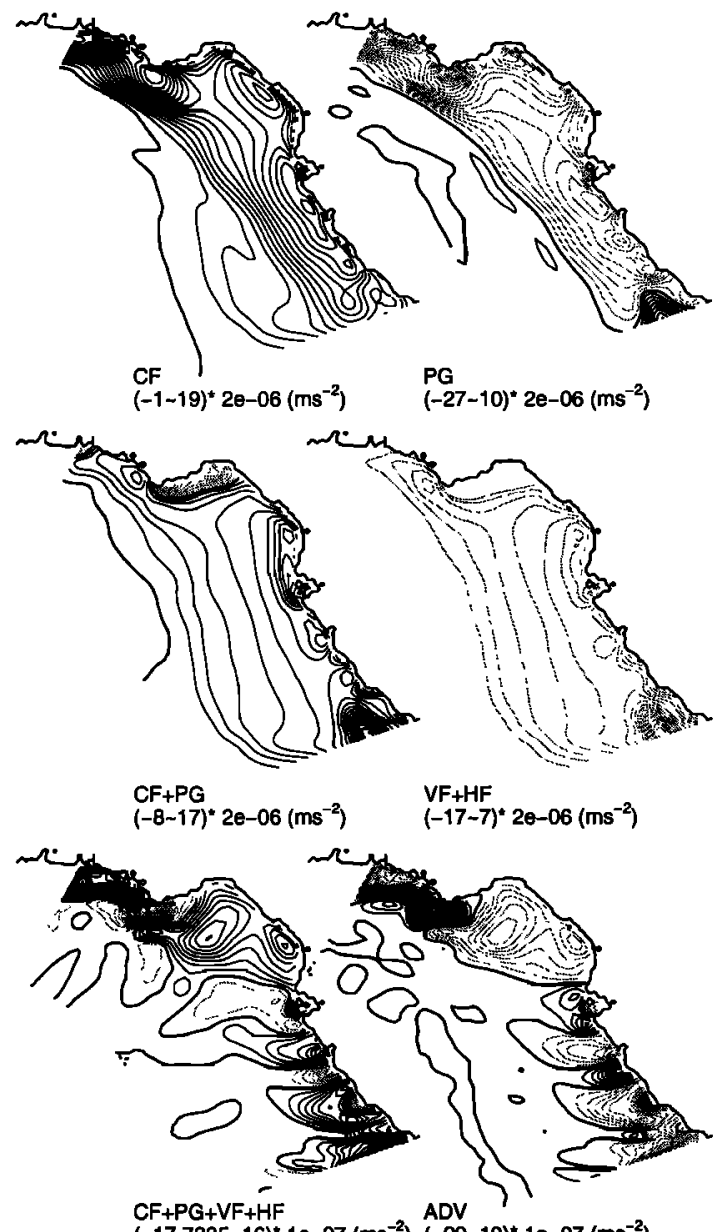

$(-17.7895-16)^{*} 1 e-07\left(\mathrm{~ms}^{-2}\right) \stackrel{A D V}{(-20-19)^{*}} 1 \theta-07\left(\mathrm{~ms}^{-2}\right)$

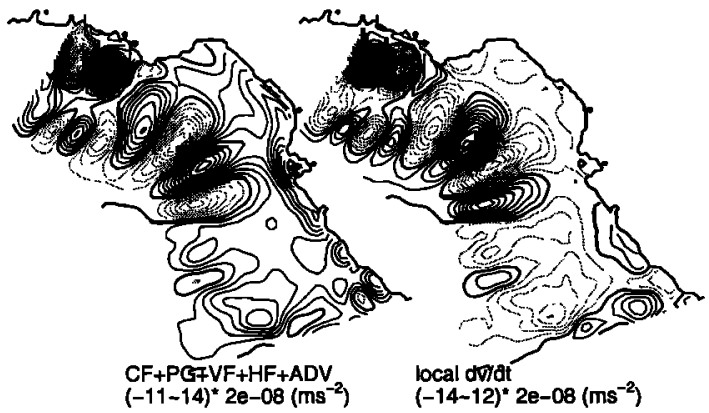

Figure 4. The systematic momentum balance closure in the across-shelf direction from the southeastward alongshore wind case on day 12 for the near-surface $\sigma$ coordinate level 2 . CF, PG, VF, HF, and ADV denote the Coriolis, pressure gradient, vertical eddy friction, horizontal friction, and advective acceleration terms, respectively.
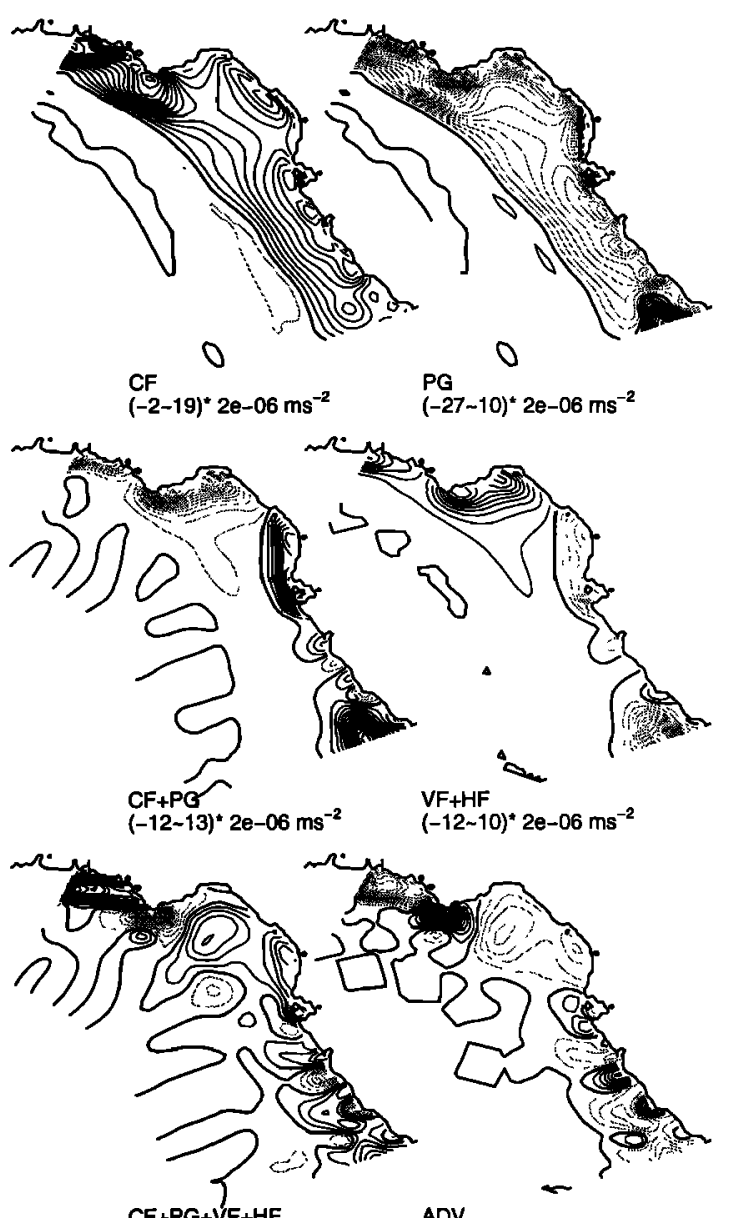

$C F+P G+V F+H F$
$(-18-10)^{*} 1 e-07 \mathrm{~ms}^{-2}$

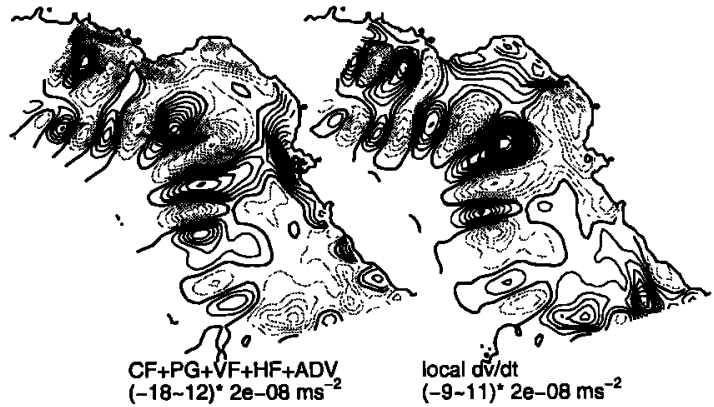

Figure 5. Similar to Figure 4 but for the middle $\sigma$ coordinate level 8 fields.

is the fact that the flow field, and hence its momentum structure, is fully three dimensional. To further understand the spatial variation of the momentum balance, we explore the three-dimensional momentum structure by sampling on different sigma coordinate levels and then systematically showing how momentum balance is achieved on these levels. The relative importances of the individual terms in the momentum balance at the first $\sigma$ level below the surface are given in Table 1. For the quasi steady state the Coriolis, pressure gradient, and vertical turbulent friction terms are the primary ones, with the local acceleration, advective acceleration, and horizontal friction terms being at least an order of magnitude smaller. Other levels show similar order of magnitude relationships.

The quasi steady state momentum balances in the acrossshelf direction at the near-surface, middle, and near-bottom $\sigma$ 


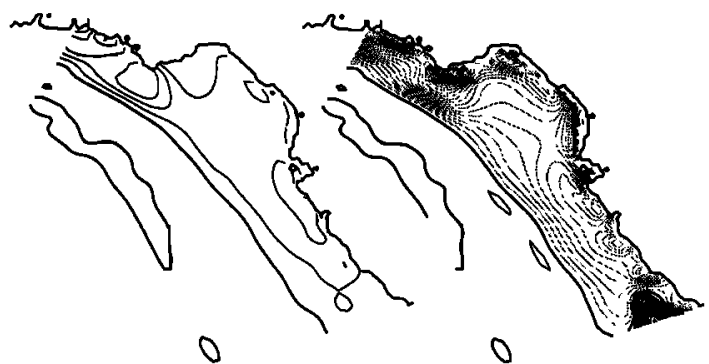

$\begin{array}{ll}\mathrm{CF} & \mathrm{PG} \\ (-1-5)^{*} 2 e-06 \mathrm{~ms}^{-2} & (-27-10)^{*} 2 e-06 \mathrm{~ms}^{-2}\end{array}$

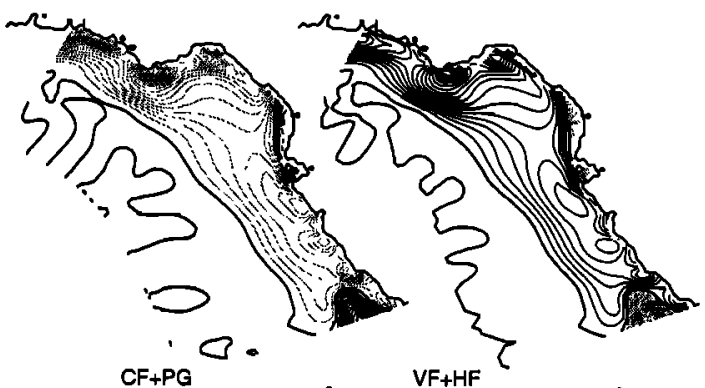

$(-20-11)^{*} 2 \theta-06 \mathrm{~ms}^{-2} \quad(-13-18)^{*} 2 \theta-06 \mathrm{~ms}^{-2}$

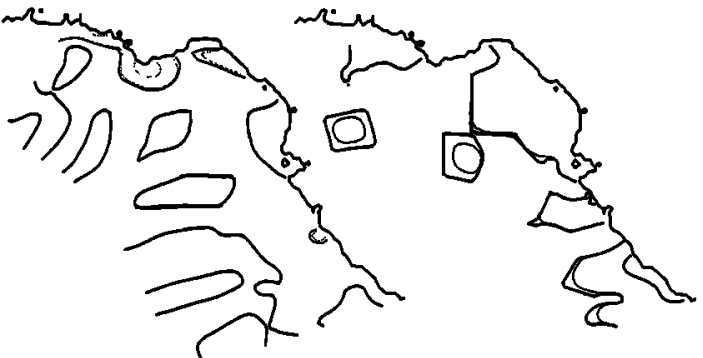

$\mathrm{CF}+\mathrm{PG}+\mathrm{VF}+\mathrm{HF} \quad \mathrm{ADV}$

$(-3-1)^{*} 1 \theta-07 \mathrm{~ms}^{-2} \quad(-1-1)^{*} 1 \theta-07 \mathrm{~ms}^{-2}$

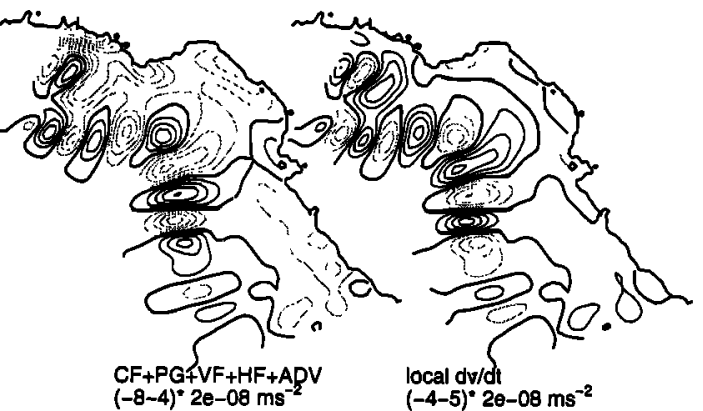

Figure 6. Similar to Figure 4 but for the near-bottom $\sigma$ coordinate level 15 fields.

coordinate levels are illustrated in Figures 4-6, respectively. The method of presentation is as follows. Eight diagrams are shown in Figures 4-6. On the top left is the Coriolis term and on the top right is the pressure gradient term. Below these on the left is their sum or the residual from a geostrophic balance. On the right is the friction term (primarily vertical friction) which is of next importance in magnitude. Each successive term on the left is the sum of the terms above (or the residual of those terms), and in this manner we observe systematic closure of the momentum balance. Generally, the order of importance in the quasi steady state is the Coriolis, pressure gradient, friction (primarily vertical), advective acceleration, and last the local acceleration terms. With the pressure gradient being depth independent versus all other terms being depth dependent, the extent of the flow field geostrophy also varies with depth. At middepth (Figure 5) the flow tends to be geostrophic except where the coastline geometry changes. Time-dependent effects in this quasi steady state are limited to the shelf break region, but even there they are 2 orders of magnitude reduced from the geostrophic terms. In contrast with the middle level the near-surface (Figure 4) and nearbottom (Figure 6) levels show large ageostrophic effects that are primarily due to vertical friction. As such, the signs of the frictional terms are opposite near the top and bottom of the water column. The fact that the frictional term near the bottom arises by virtue of the coastal jet is evidenced in the similarity between the spatial patterns of the pressure gradient and friction terms. Near the bottom the Coriolis term is nearly zero since the coastal jet must approach zero at the bottom. Hence the balance there is primarily between the pressure gradient
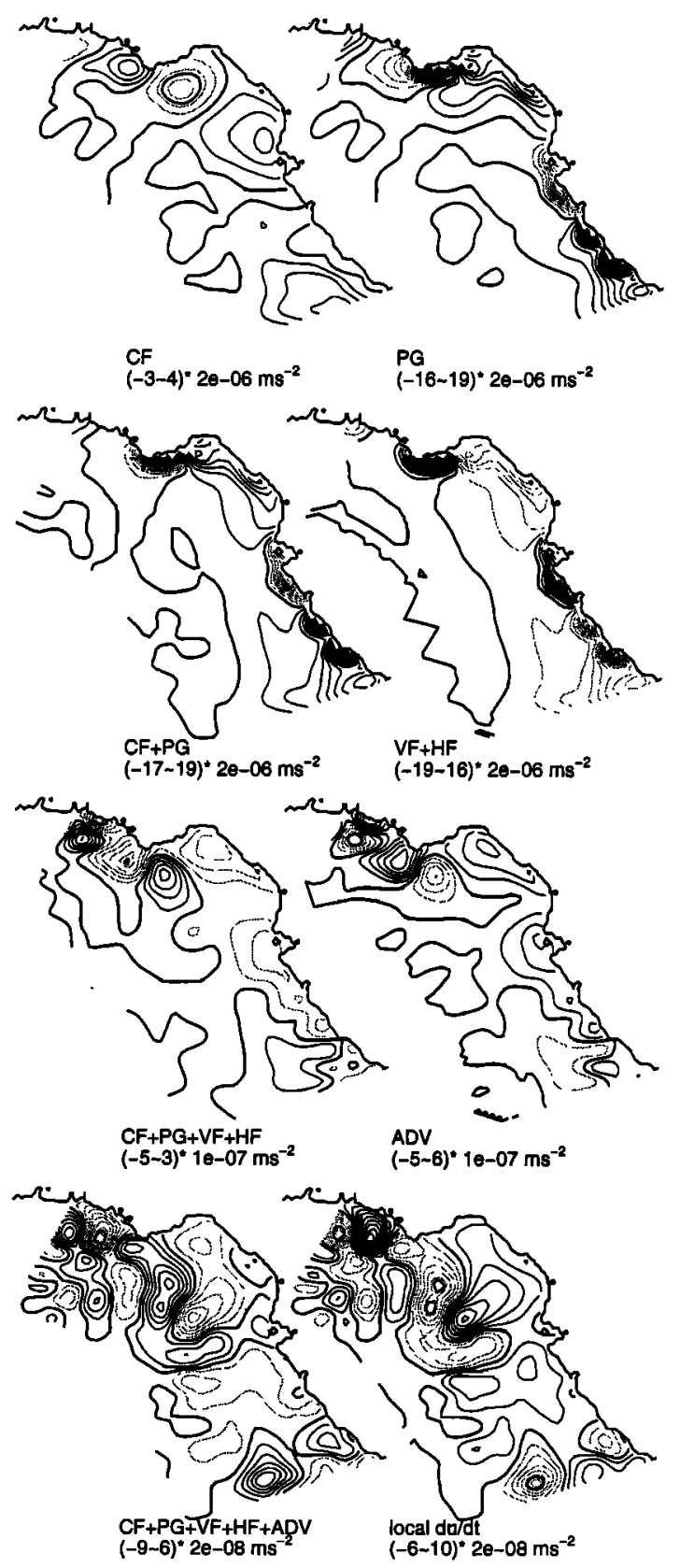

Figure 7. Similar to Figure 4 but for the middle $\sigma$ coordinate level 8 fields in the alongshore direction. 

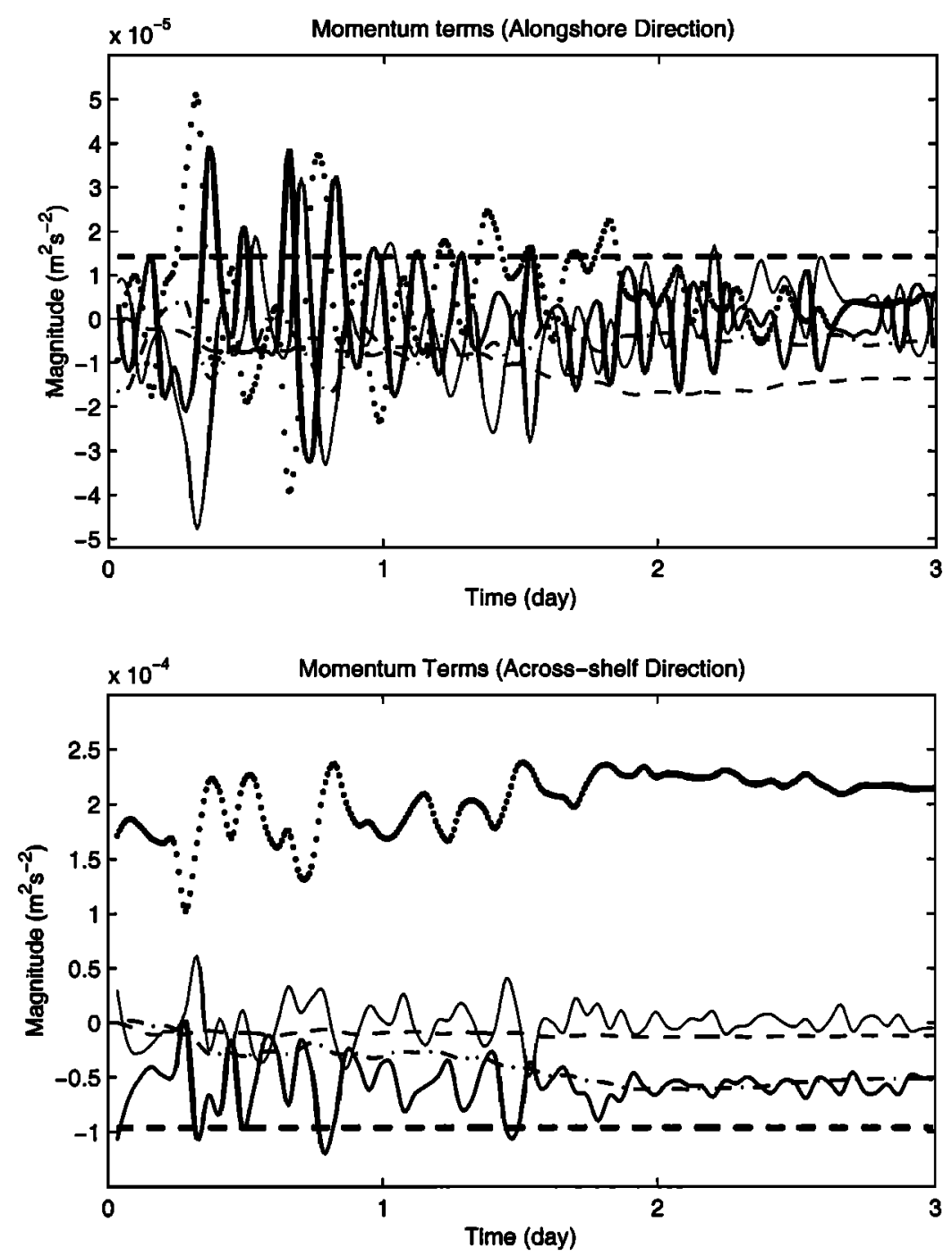

Figure 8. Initial evolution of the depth-integrated momentum terms for both the (top) alongshore and (bottom) across-shelf momentum equations from the offshore wind case at a site offshore from Sarasota at $15.3 \mathrm{~m}$ depth. The pressure gradient term is the bold dotted line, the Coriolis term is the dash-dotted line, the wind stress term is the bold dashed line, the bottom stress term is the thin dashed line, the advection term is the bold solid line, and the local acceleration term is the thin solid line.

and the vertical friction. Elsewhere in the water column the primary balance is between the Coriolis, pressure gradient, and vertical friction terms. As at midlevel, ageostrophic effects are also large where the coastline geometry changes, and this is particularly so in the Big Bend and Florida Bay regions.

The residual of the three primary terms is an order of magnitude less than these terms individually, and it tends to be balanced by the advective acceleration term. Moreover, the pattern for this advective acceleration is coastally trapped. These stationary, wave-like features appear to emanate from the regions of coastline geometry change in the northern Big Bend and Florida Bay. They are largest at the surface where the velocity magnitude is largest, and they have a structure that is distinctly different from the local acceleration term.

Contributing last to the momentum balance closure is the local acceleration term whose pattern is primarily centered about the shelf break. These local accelerations are related to two-dimensional eddies (modified by friction near the bottom) that arise as a consequence of vortex stretching due to bottom
Ekman layer flows across steep topography. The remaining small residual after the summation of all terms (not shown, but 4 orders of magnitude smaller than the primary terms) is due to a combination of numerical truncation and computation errors and filtering of inertial or shorter-period oscillations.

The momentum structures in the alongshore direction are spatially more complicated than those in the across-shelf direction, as shown for the middepth level in Figure 7 . The presentation format and the ordering of magnitudes for the terms are similar to those of the across-shelf direction. The importance of the coastline geometry is again evident. The Coriolis distribution is determined by the flow regulation of the curved coastline, particularly within the Big Bend and Florida Bay regions. These coastline curvatures impart three dimensionality to the flow field and its associated momentum balance. Given these three-dimensional flow field responses, the pressure gradient, friction, and advective accelerations must all adjust. Over the inner shelf region the alongshore variations in the pressure gradient and friction are particularly important as 

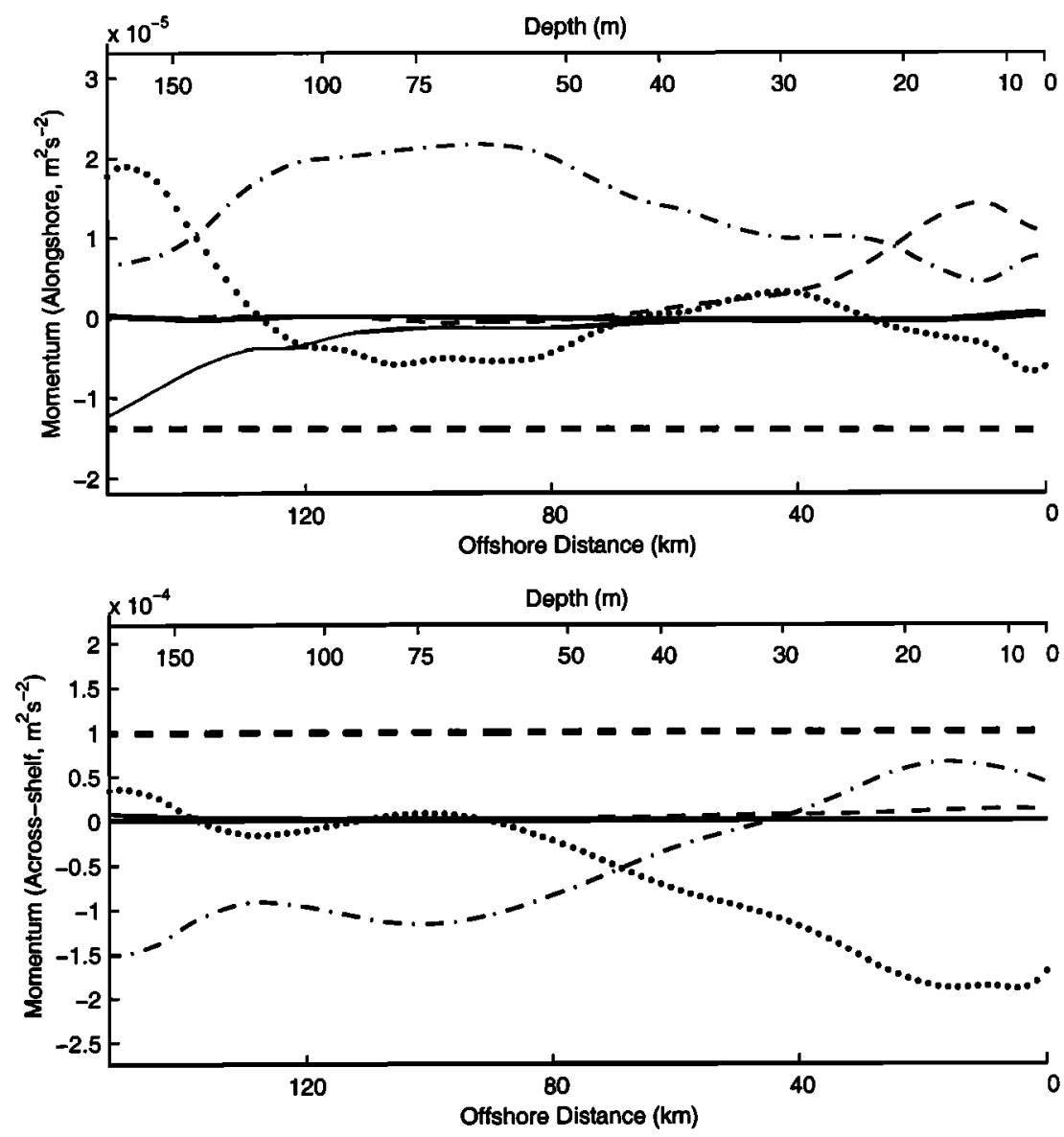

Figure 9. The across-shelf distributions of the depth-integrated momentum terms from both the (top) alongshore and (bottom) the across-shelf momentum equations on day 12 sampled offshore from Sarasota for the offshore wind case. The pressure gradient term is the bold dotted line, the Coriolis term is the dash-dotted line, the wind stress term is the bold dashed line, the bottom stress term is the thin dashed line, the advection term is the bold solid line, and the local acceleration term is the thin solid line.

is also evident in the vertically integrated momentum balances. The residuals are again in the local acceleration. However, the patterns are less confined to the shelf break since steep topography inhibits across-shelf interior flow. While not shown, the near-surface and near-bottom levels have similar structures as in Figure 7. Relative to Figure 7 the near-surface level shows enhancement of the Coriolis term, and the near-bottom level shows enhancement of the friction term for the same reasons as in the across-shelf direction.

\subsection{Offshore Wind Experiment}

Similar to Figure 2 and at the same $15.3 \mathrm{~m}$ depth location offshore from Sarasota, Figure 8 shows time series of the depth-integrated momentum terms in both the alongshore and the across-shelf momentum equations for the case of offshore wind forcing. Upon application of a uniform wind stress in the across-shelf direction the initial downwind acceleration of fluid results in a nearly instantaneous (within an hour) across-shelf pressure gradient. A dimensional analysis confirms that the surface slope sets up on a timescale much shorter than necessary for the Coriolis acceleration to have any significant effect. A coastal jet then begins to form by virtue of the Coriolis term tending to oppose the pressure gradient term, and after 2 days, there is a balance primarily between the pressure gradient, Coriolis, and advective acceleration terms. In a purely two- dimensional case, Csanady [1976] argues that the steady state currents and pressure gradient responses to offshore wind forcing should be nil. The three-dimensional aspects of Florida's west coast and, in particular, the curvatures within the Big Bend region and the partial closure by the Florida Keys in the south ultimately support a coastal jet and an across-shelf pressure gradient in response to this offshore wind stress experiment since along those boundaries the stress is aligned more nearly alongshore. Achievement of this quasi steady state, however, takes more time in the offshore wind stress case than in the alongshore wind stress case because these accelerations must be communicated along the coastline. After these acceleration effects are complete, the quasi steady state at this location consists of a primary balance between the wind stress, pressure gradient, and Coriolis terms with the bottom stress term playing a secondary role.

The alongshore momentum terms show an initially evolving balance between the bottom stress and the wind stress (note that the curvilinear coordinate system is not exactly aligned with the alongshore or offshore wind stresses at this location, so there is a small alongshore component to the wind stress locally). The bottom stress is a consequence of the evolving coastal jet.

As for the alongshore wind stress experiment, the quasi 
steady state balances for the offshore wind stress also depend on water depth. Figure 9 shows how these balances vary across the shelf offshore from Sarasota for both the vertically integrated alongshore and the across-shelf momentum equations on day 12. In the across-shelf direction the middle to outer shelf shows the wind stress term primarily balancing the Coriolis term as expected from Ekman theory. The inner shelf is again a transition region, but in this case the Coriolis term decreases as the pressure gradient term increases, so that near the coast the primary balance is between the wind stress and the pressure gradient with the Coriolis term playing a secondary role. Interestingly, the sign of the Coriolis term changes midway through the inner shelf as a transition occurs from the Ekman transport tending to the right of the wind stress to the coastal jet transport tending to the right of the pressure gradient force which is largest near the coastline.

In the alongshore momentum direction all of the momentum terms are an order of magnitude smaller than in the across-shelf direction. Over the inner shelf the bottom stress term becomes of increasing importance as a consequence of the coastal jet. At midshelf the balance is primarily Ekman, and farther offshore the time-dependent local accelerations remain relatively large.

The three dimensionality of the offshore wind stress case shows features in common with the alongshore wind stress case. However, while the relative magnitudes for the momentum terms are the same (the Coriolis, pressure gradient, and vertical friction terms are the primary ones, and local acceleration, advective acceleration, and horizontal friction terms are smaller in magnitude), the absolute magnitudes differ with wind stress direction (compare the Table 2 values for the offshore case with the Table 1 values for the alongshore case).

The quasi steady state momentum balances in the acrossshelf direction at the near-surface, middle, and near-bottom $\sigma$ coordinate levels are illustrated in Figures 10-12. The ordering of closure is similar to the previous case, but the patterns for the individual terms are different. Most apparent near the surface is the mismatch between the Coriolis and pressure gradient terms. The Coriolis term reverses sign from the Ekman tendency in deep water to the coastal jet tendency in shallow water as previously explained. Thus the response of the shelf to offshore wind stress is generally more ageostrophic then the response to alongshore wind stress, and this is evidenced in the friction terms whose influence pervades the entire domain. The pressure gradient term also reverses sign along the Panhandle coast indicative of the flow bifurcation in

Table 2. Ranges of the Momentum Terms in the AcrossShelf and Alongshore Momentum Equations at the Subsurface From the Offshore Wind Forcing Experiment

\begin{tabular}{|c|c|c|c|c|}
\hline \multirow[b]{2}{*}{ Term } & \multicolumn{2}{|c|}{$\begin{array}{l}\text { Across-Shelf } \\
\text { Momentum } \\
\text { Equation }\end{array}$} & \multicolumn{2}{|c|}{$\begin{array}{c}\text { Alongshore } \\
\text { Momentum } \\
\text { Equation }\end{array}$} \\
\hline & $\begin{array}{l}\text { Range, } \\
\mathrm{m} \mathrm{s}^{-2}\end{array}$ & Rank & $\begin{array}{l}\text { Range, } \\
\mathrm{m} \mathrm{s}^{-2}\end{array}$ & Rank \\
\hline Local accele & $2.6 \times 10^{-7}$ & 3 & $2.4 \times 10^{-7}$ & 2 \\
\hline Advective acceleration & $1.1 \times 10^{-6}$ & 2 & $4.5 \times 10^{-7}$ & 2 \\
\hline Horizontal friction & $1.1 \times 10^{-7}$ & 3 & $0.8 \times 10^{-7}$ & 2 \\
\hline Coriolis & $2.5 \times 10^{-5}$ & 1 & $1.0 \times 10^{-5}$ & 1 \\
\hline Pressure gradient & $2.5 \times 10^{-5}$ & 1 & $1.3 \times 10^{-5}$ & 1 \\
\hline Vertical eddy friction & $1.8 \times 10^{-5}$ & 1 & $1.4 \times 10^{-5}$ & 1 \\
\hline
\end{tabular}
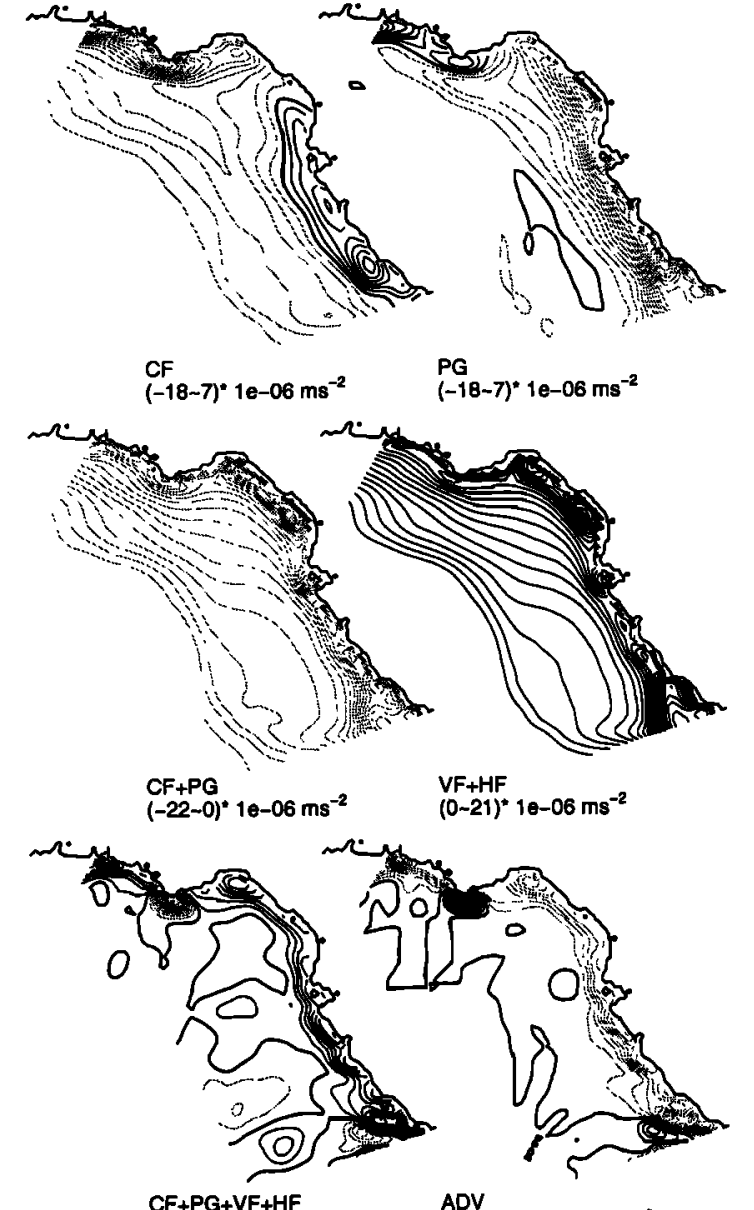

$\begin{array}{ll}C F+P G+V F+H F \\ (-12-11)^{*} 5 e-08 \mathrm{~ms}^{-2} & A D V \\ (-12-10)^{*} 5 e-08 \mathrm{~ms}^{-2}\end{array}$

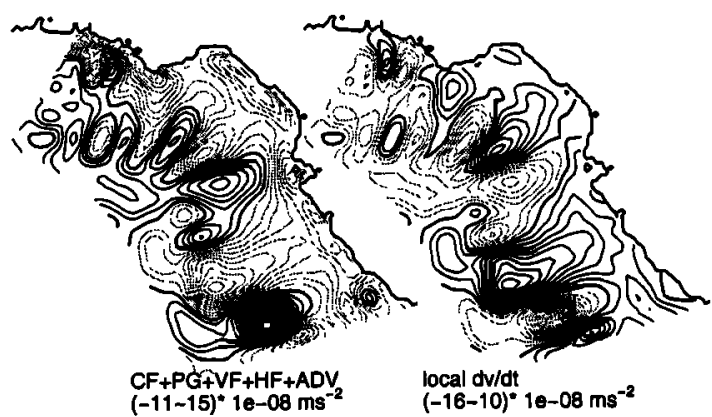

Figure 10. The systematic momentum balance closure in the across-shelf direction from the offshore wind case on day 12 for the near-surface $\sigma$ coordinate level 2. CF, PG, VF, HF, and ADV denote the Coriolis, pressure gradient, vertical eddy friction, horizontal friction, and advective acceleration terms, respectively.

the Big Bend as a consequence of coastline geometry. Advective acceleration effects are proportionately smaller than in the alongshore wind stress case, and these effects are again limited to the inner shelf region, particularly at points of large coastline curvature. Local acceleration variations are again largest over the shelf break. Going through the water column from the near-surface diagrams to the near-bottom diagrams, the Coriolis term decreases while the friction (primarily vertical) term increases (Figures 10 and 12).

The momentum structures in the alongshore direction have a less coherent spatial organization as illustrated at midlevel in 


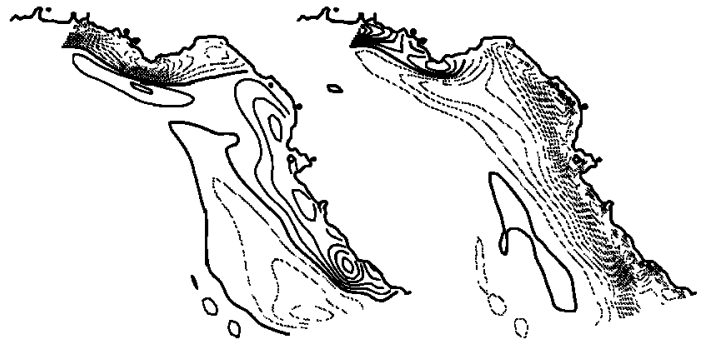

$\begin{array}{ll}\text { CF } \\ (-10-6) * 1 e-06 \mathrm{~ms}^{-2} & \text { PG } \\ (-18-7)^{*} & 1 \mathrm{e}-06 \mathrm{~ms}^{-2}\end{array}$
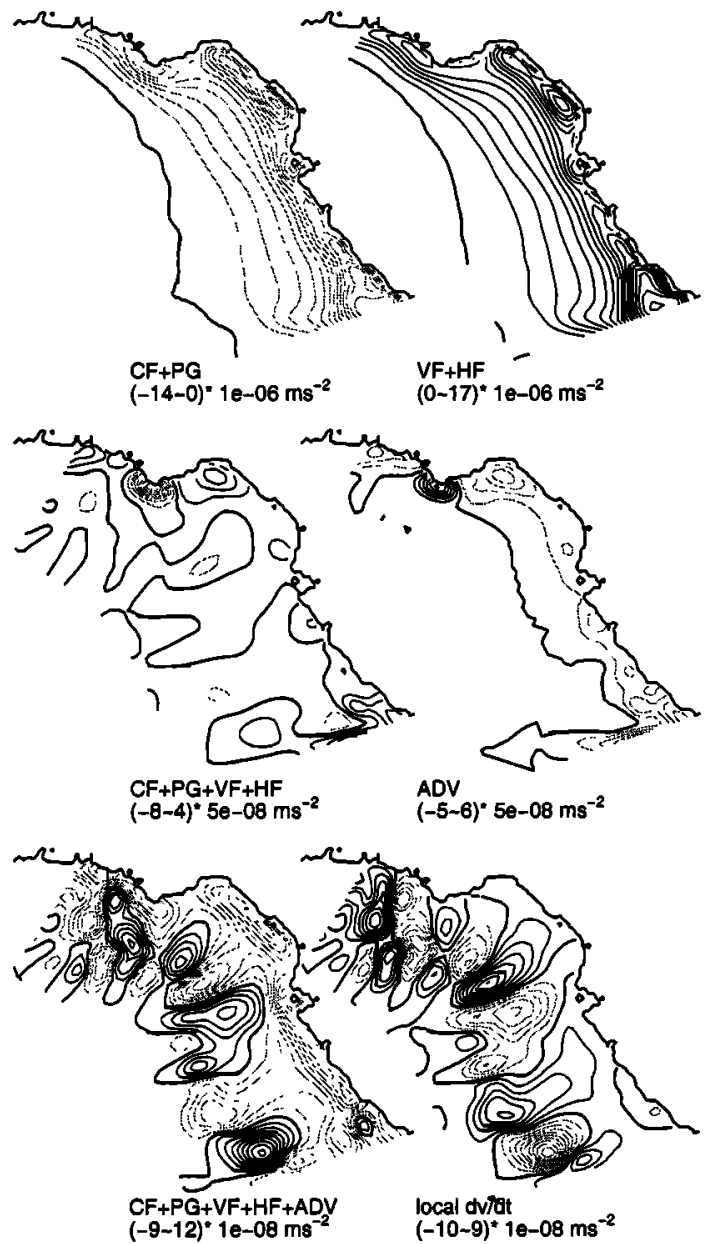

Figure 11. Similar to Figure 10 but for the middle $\sigma$ coordinate level 8 fields.

Figure 13. The changes in coastline geometry give rise to alongshore variations in the pressure gradient term and hence in the Coriolis and friction terms for the primary balance. The largest values for these terms are in the Big Bend and Florida Bay regions, and these regions play a role in maintaining the coastal jet.

\section{Turbulent Eddy Viscosity}

With friction playing an important role in the threedimensional structures of the flow fields and their momentum balances, proper parameterizations for the turbulent mixing processes are essential for modeling the continental shelf circulation. The POM uses the Mellor-Yamada level 2.5 turbulence closure submodel [Mellor and Yamada, 1982] to param- eterize vertical mixing. This section explores the turbulent mixing characteristics of the WFS responses to alongshore and offshore wind forcing, as represented by the turbulent kinetic energy $\left(q^{2}\right)$ and the vertical turbulent eddy coefficient $\left(K_{m}\right)$ from the Mellor-Yamada level 2.5 closure submodel. The horizontal eddy coefficient $\left(A_{m}\right)$ from the Smagarinsky formulation is also displayed.

\subsection{Southeastward Alongshore Wind Experiment}

Along with the flow fields the turbulence characteristics also evolve rapidly toward a quasi steady state while maintaining fairly stable spatial patterns. These patterns for $q^{2}, K_{m}$, and $A_{m}$ are shown in Figure 14 for the Sarasota across-shelf section and in Figure 15 for $\sigma$ coordinate level planar sections at the
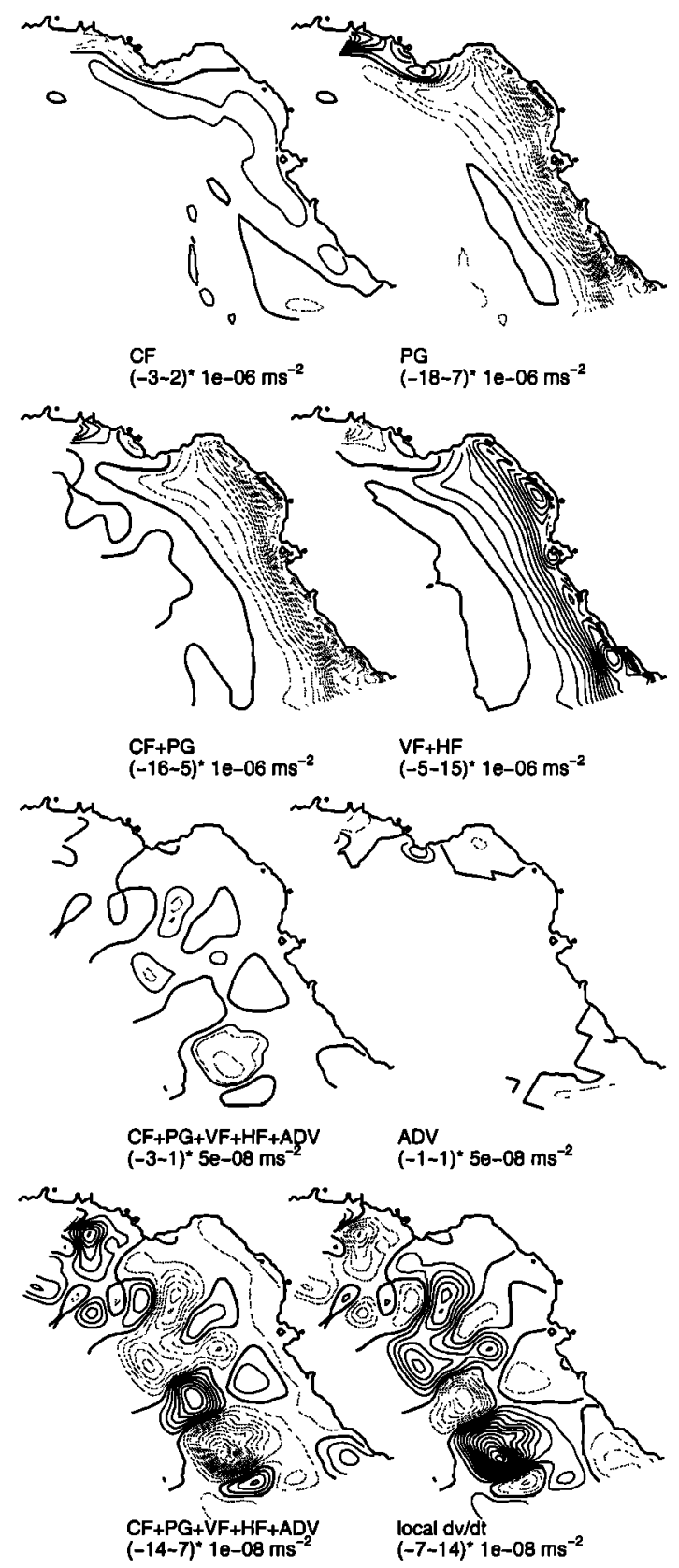

Figure 12. Similar to Figure 10 but for the near-bottom $\sigma$ coordinate level 15 fields. 
near surface, middepth, and near bottom; all are sampled on day 12 .

The vertical distributions of both $q^{2}$ and $K_{m}$ are consistent with those found in other modeling studies [e.g., Allen et al., 1995]. Here $q^{2}$ tends to be maximum near the surface and within the coastal jet. Since $K_{m}$ derives from the product of $q^{2}$ and the turbulence length scale that is zero at both the surface and the bottom, $K_{m}$ tends to have a subsurface maximum. This subsurface maximum (centered at about $10 \mathrm{~m}$ depth) then extends across the entire shelf domain. Appreciable values of $A_{m}$ are limited to the near-shore region of shallowest water. Even there the role of horizontal friction is secondary to vertical friction.

The distributions on $\sigma$ levels must be viewed relative to these findings at absolute depths. Thus the distribution of $q^{2}$ on the
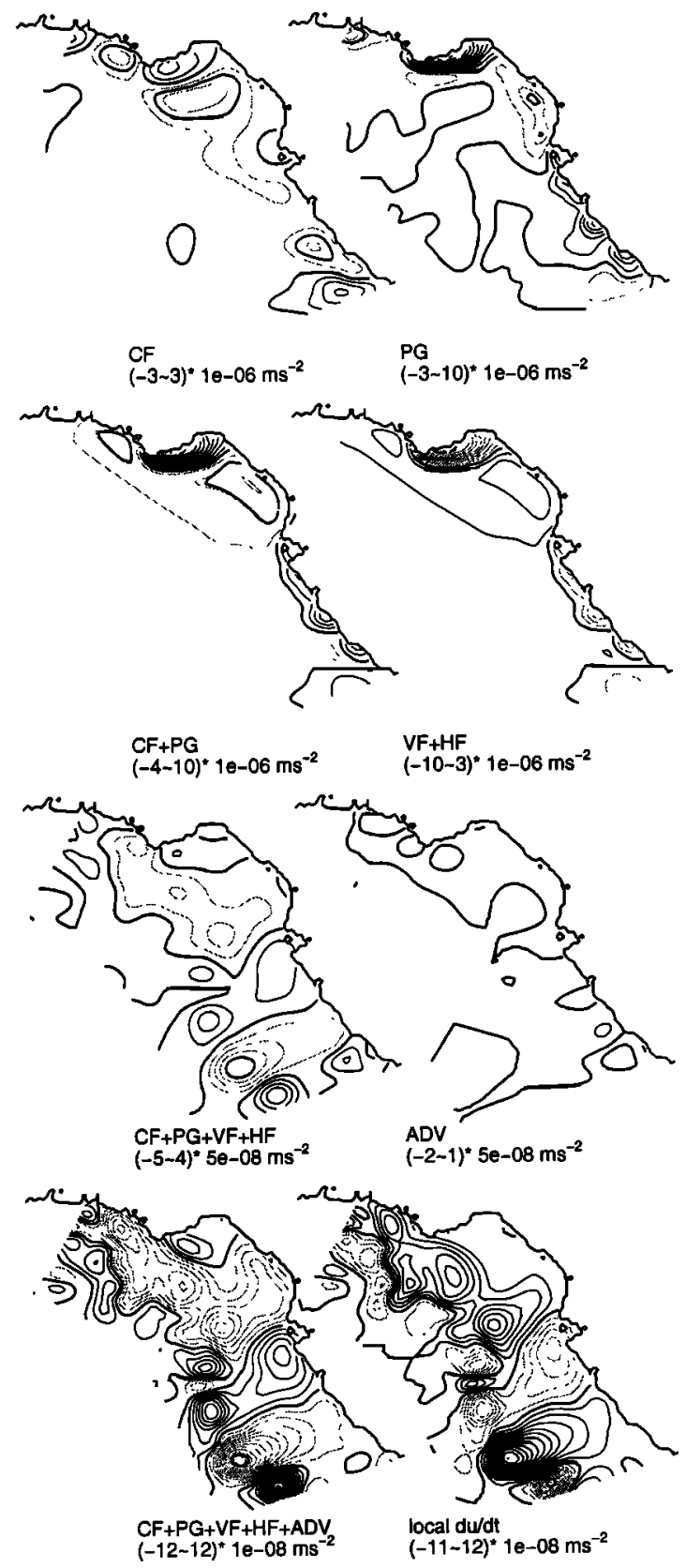

Figure 13. Similar to Figure 10 but for the middle $\sigma$ coordinate level 8 fields in the alongshore direction.

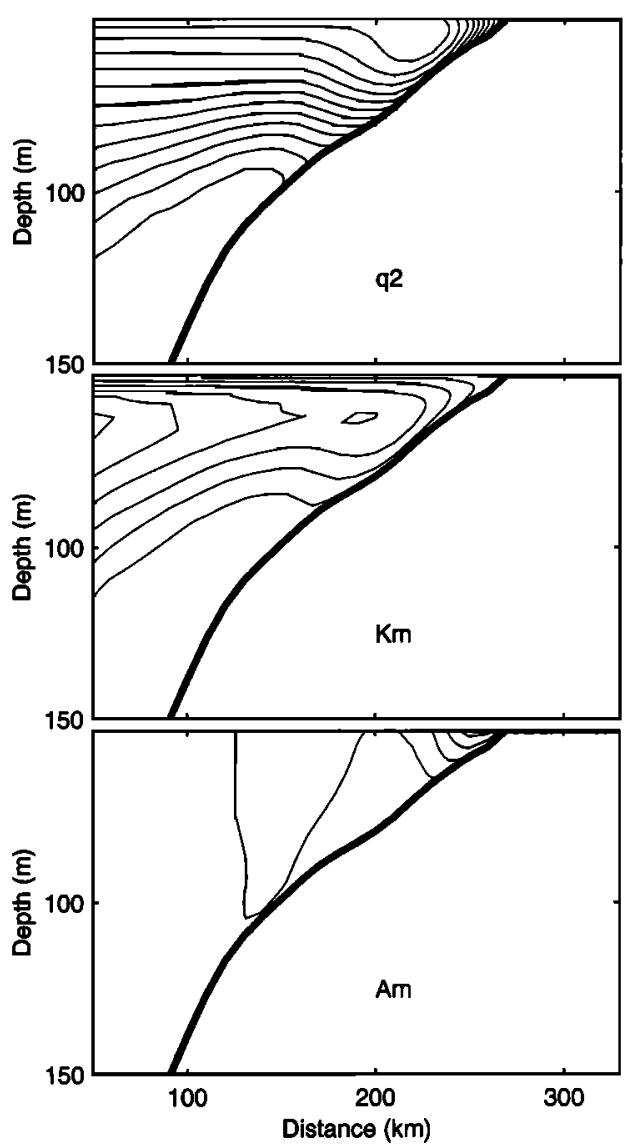

Figure 14. Vertical structures of turbulent kinetic energy $q^{2}$, the vertical eddy coefficient $K_{m}$, and the horizontal mixing coefficient $A_{m}$ on day 12 from the southeastward alongshore wind experiment. The contour intervals for $q^{2}, K_{m}$, and $A_{m}$ are $5 \times 10^{-5} \mathrm{~m}^{2} \mathrm{~s}^{-2}, 2 \times 10^{-3} \mathrm{~m}^{2} \mathrm{~s}^{-1}$, and $16.67 \mathrm{~m}^{2} \mathrm{~s}^{-1}$, respectively.

middepth and bottom levels reflects the fact that these levels occur at increasingly deeper depths farther offshore. Interesting in the planar views is the appearance of the coastal jet in the $q^{2}$ distributions as expected. Similar statements apply to $K_{m}$. At middepth, $K_{m}$ is largest where the coastal jet is most developed; near bottom, $K_{m}$ is small because the turbulence length scale is small; and near surface, $K_{m}$ appears to increase but only because the absolute depth increases. Since the stress derives from the product of $K_{m}$ and the vertical shear, the stress and its divergence (the frictional force) depend upon the turbulence parameterization. If the required frictional force is large where $K_{m}$ is small, the shear will have to be large and conversely. Thus the internal structure of the flow field depends critically on the turbulence parameterizations. Ultimately, these POM flow fields will have to be assessed relative to in situ observations.

\subsection{Offshore Wind Experiment}

Similar presentations for the turbulence characteristics under offshore wind stress forcing are given in Figures 16 and 17 for the Sarasota across-shelf section and for the $\sigma$ level planes, respectively. The basic patterns on day 12 are again representative of the rapid evolution toward a quasi steady state. Here $q^{2}$ shows maximum values near the surface, but there is no outstanding feature associated with the (more limited) coastal 


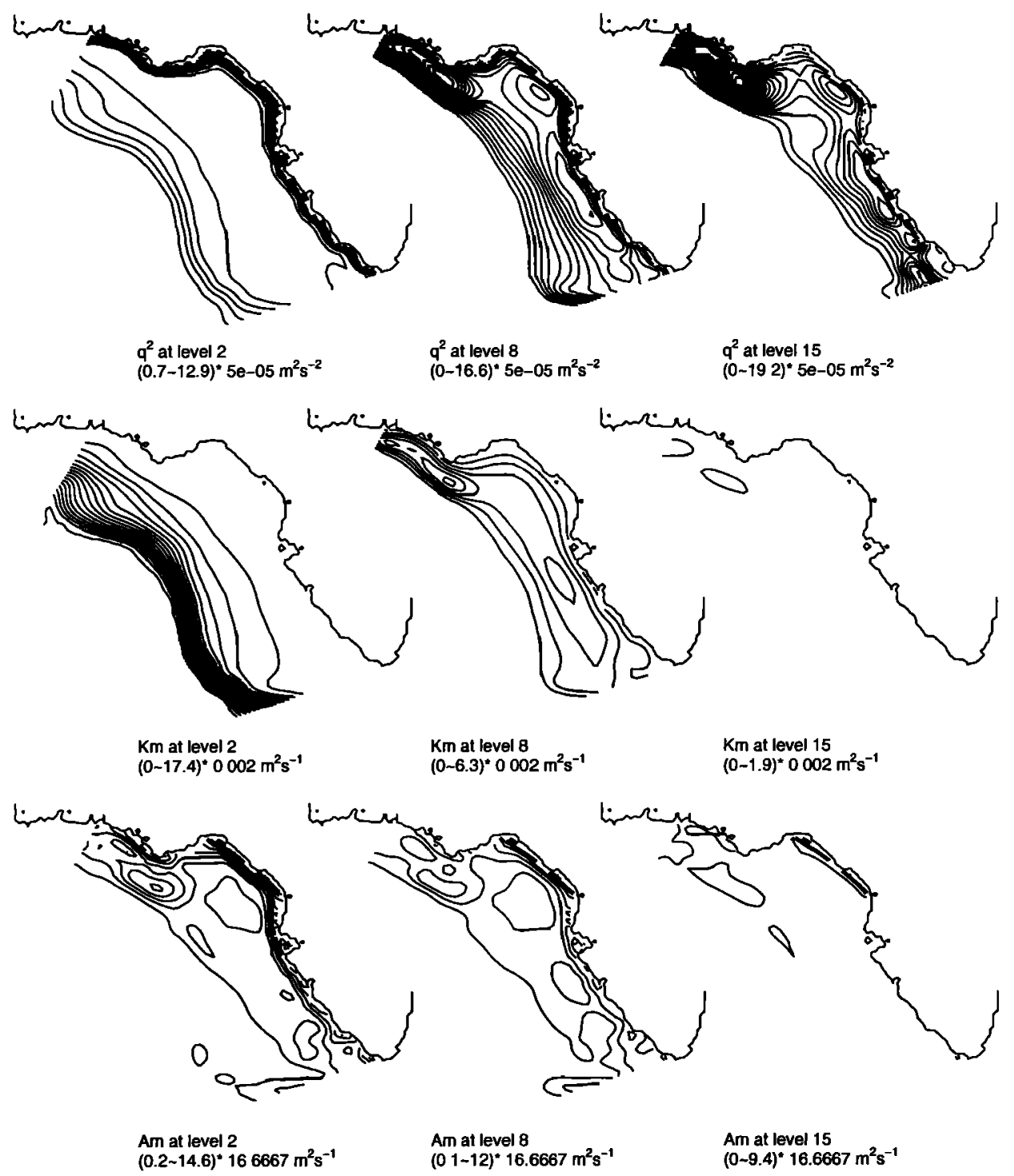

Figure 15. The $\sigma$ level fields of turbulent kinetic energy $q^{2}$, the vertical eddy coefficient $K_{m}$, and the horizontal mixing coefficient $A_{m}$ on day 12 from the southeastward alongshore wind experiment. The contour intervals for $q^{2}, K_{m}$, and $A_{m}$ are $5 \times 10^{-5} \mathrm{~m}^{2} \mathrm{~s}^{-2}, 2 \times 10^{-3} \mathrm{~m}^{2} \mathrm{~s}^{-1}$, and $16.67 \mathrm{~m}^{2} \mathrm{~s}^{-1}$, respectively.

jet. Moreover, $q^{2}$ continues to increase in magnitude with distance offshore. This is a consequence of the vertical shear being larger for the offshore wind stress case over that for the alongshore wind stress case. As a corollary, $K_{m}$ also increases with distance offshore consistent with the finding that the flow fields for the offshore wind stress case are more ageostrophic than those for the alongshore wind stress case. Comparable between the two cases, however, is the finding that $\boldsymbol{A}_{m}$ is similarly small and limited to the near-shore, shallow water region.

\section{Other Experiments}

Complementing the two benchmark runs, five additional sets of experiments are considered that test the model sensitivity to vertical mixing parameterization and wind stress magnitude. Three of these replace the default Mellor-Yamada turbulence closure submodel with constant eddy coefficients set at values of $0.05 \mathrm{~m}^{2} \mathrm{~s}^{-1}, 0.005 \mathrm{~m}^{2} \mathrm{~s}^{-1}$, or $0.0005 \mathrm{~m}^{2} \mathrm{~s}^{-1}$. The other two retain the default turbulence closure submodel for eddy coefficient but vary the wind stress magnitude by either halving $(0.5$ dyn $\left.\mathrm{cm}^{-2}\right)$ or doubling $\left(2 \mathrm{dyn} \mathrm{cm}^{-2}\right)$ it relative to the bench-

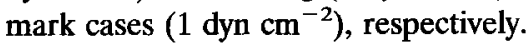

The results of these sensitivity tests are presented in Figure 18 with respect to the across-shelf distributions of the depthintegrated momentum terms in the across-shelf direction off Sarasota at day 12 . The left-hand diagrams are for the experiments with alongshore wind forcing, and the right-hand diagrams are for experiments with offshore wind forcing. From top to bottom on each side the first three rows show the results with constant eddy coefficients of $0.05 \mathrm{~m}^{2} \mathrm{~s}^{-1}, 0.005 \mathrm{~m}^{2} \mathrm{~s}^{-1}$, $0.0005 \mathrm{~m}^{2} \mathrm{~s}^{-1}$, and the last two rows show the results with either the halved or doubled wind stress magnitudes.

For alongshore wind forcing the basic geostrophic relationship holds in all cases. However, several distinguishing features occur. The magnitude of the eddy coefficient affects the magnitudes of the momentum terms. The smaller the eddy coeffi- 
cient is, the smaller the damping is and hence the larger the terms. Decreasing the eddy coefficient also decreases the inner shelf width since the inner shelf is the region over which the surface and bottom Ekman layers interact. Decreasing the eddy coefficient decreases the surface and bottom Ekman layers and hence the region over which they interact. Increasing the wind stress magnitude increases the response intensity and the width of the responsive region. Increasing the stress magnitude essentially increases the turbulence level and hence the parameterized eddy coefficients. Thus, despite the advective acceleration terms being relatively small the model response is inherently nonlinear by virtue of the turbulence submodel. Additionally, the bottom stresses in the alongshore direction, while not shown, increase with either increasing eddy coefficient or forcing magnitude.

With the WFS response to offshore wind forcing being more turbulent than for alongshore wind forcing, a change in vertical eddy coefficient parameterization largely impacts the momentum balance structure (right diagrams of Figure 18). In the extreme case with an eddy coefficient of $0.05 \mathrm{~m}^{2} \mathrm{~s}^{-1}$ the Coriolis and pressure gradient terms have maxima at depths exceeding $100 \mathrm{~m}$, as opposed to the near-shore region, suggesting that the largest currents and surface deformations occur far offshore. Obviously, such response is contradictory to observations. Reducing the eddy coefficient gives results that are more consistent with Ekman theory and with results from the default model closure.

\section{Summary and Discussion}

Justified by the role of the circulation on topics such as sediment or hazardous material transports, harmful algal blooms, and fisheries resources, programs for improved description and understanding of the west Florida continental shelf (WFS) circulation are underway with a combination of in situ and remotely sensed measurements and numerical circulation model applications. Since the WFS is forced seasonally and synoptically by a complex superposition of local surface inputs and density and pressure inputs from seaward of the shelf break, our modeling approach is to first isolate individual influences in order to provide a context for interpreting more complete simulations or forecasts. Herein we consider surface wind-forced initial value problems intended to provide such context for the WFS response to the synoptic scale weather fronts that typically transit the region in late fall through early spring. Li and Weisberg [1999], referred to as Part 1, describe the kinematics of the flow field responses, and the present paper adds discussions on the dynamical structures of these responses. For simplicity, we focus on spatially homogeneous, upwelling favorable wind stresses directed either alongshore or offshore (relative to west coast of the Florida Peninsula) under a constant density setting. Even with these simplifications the flow fields are fully three-dimensional, being affected primarily by the coastline and isobath geometries along with the surface and bottom frictional boundary layers.

We begin with vertically integrated momentum balances in time series form at an inner shelf location to describe how the flow field rapidly evolves to a quasi steady state. We then show how these quasi steady state vertically integrated balances vary across the shelf thus defining inner, middle, and outer shelf regions as dynamical regimes. For the case of alongshore wind stress the inner shelf is the transition region between the coastline and the point where the offshore-directed Ekman trans-

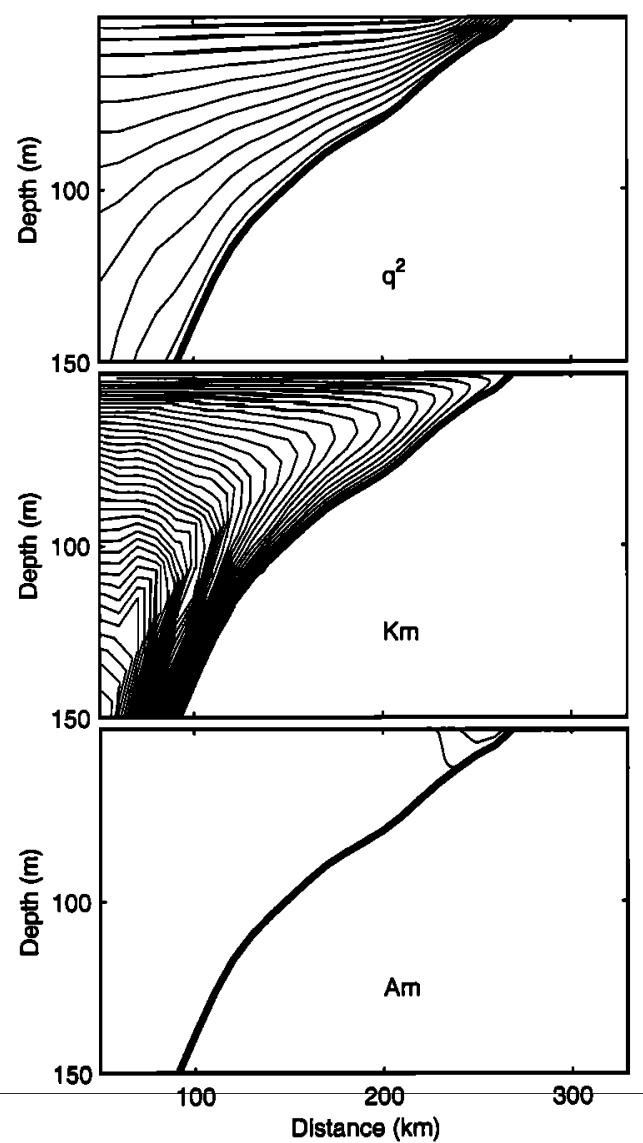

Figure 16. Vertical structures of turbulent kinetic energy $q^{2}$, the vertical eddy coefficient $K_{m}$, and the horizontal mixing coefficient $A_{m}$ on day 12 from the offshore wind experiment. The contour intervals for $q^{2}$ and $A_{m}$ are the same as in Figure 14 , but for $K_{m}$ the contour interval is $4 \times 10^{-3} \mathrm{~m}^{2} \mathrm{~s}^{-1}$.

port balances the alongshore wind stress. Within this region the divergence of the offshore transport sets up the sea level and an associated coastal jet. The coastal jet, in turn, effects a bottom Ekman layer. Consistent with Mitchum and Clarke [1986] and Lentz [1995], the interaction between the surface and bottom Ekman layers defines the inner shelf, but contrary to those authors a blocking of the Ekman transport does not occur. The flow field, even with the subtle WFS coastline geometry variations, is fully three-dimensional in our experiments. As a corollary, while bottom stress takes on an increasingly important role in tending to balance the surface stress in the alongshore direction [e.g., Mitchum and Sturges, 1982] as depth decreases toward the shoreline, it never fully balances the surface stress. For an across-shelf section sampled off Sarasota, the inner shelf extends out to about the $50 \mathrm{~m}$ isobath with the coastal jet centered in between at about the $25-30 \mathrm{~m}$ isobaths where the bottom stress and Coriolis terms are of equal size and where the alongshore pressure gradient is also a factor. This finding is supported by inner shelf observations in progress that will be reported on separately. Using satellite advanced very high resolution radiometer (AVHRR) SST and in situ data, R. H. Weisberg et al. (An upwelling case study on Florida's west coast, submitted to the Journal of Geophysical Research, 1999) provide a WFS upwelling case study that also supports the model findings.

Three dimensionally, as viewed on different $\sigma$ coordinate 


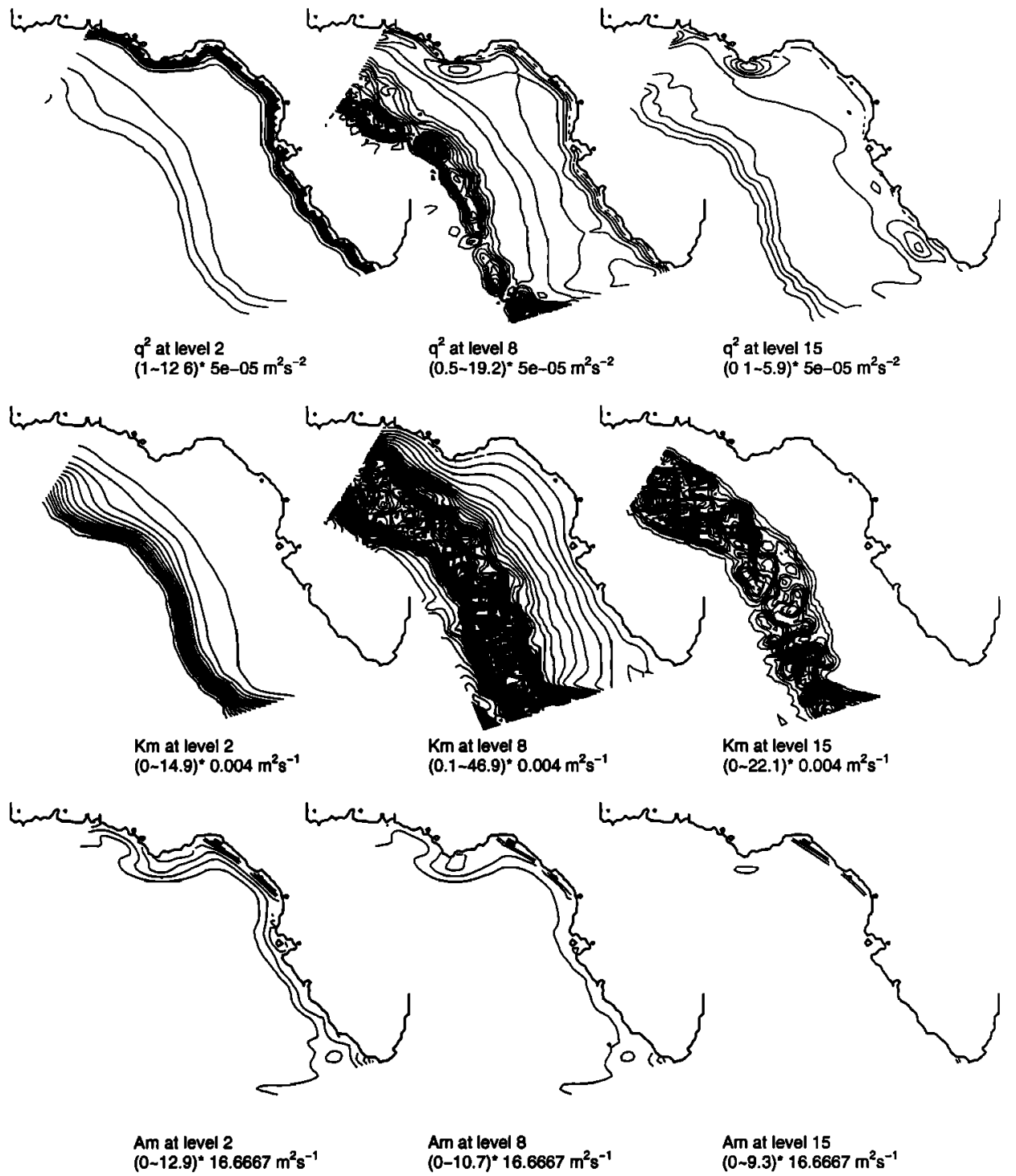

Figure 17. The $\sigma$ level fields of turbulent kinetic energy $q^{2}$, the vertical eddy coefficient $K_{m}$, and the horizontal mixing coefficient $A_{m}$ on day 12 from the offshore wind experiment. The contour intervals for $q^{2}$ and $A_{m}$ are the same as in Figure 15, but for $K_{m}$ the contour interval is $4 \times 10^{-3} \mathrm{~m}^{2} \mathrm{~s}^{-1}$.

surfaces, the momentum balance depends upon local circulation features that vary from point to point. We describe the systematic closure of the momentum balance everywhere within the model domain. The primary tendency is for a geostrophic balance almost everywhere except as modified by the surface and bottom boundary layers. Exceptions are the regions of largest coastline curvature found in the Big Bend region in the north and the combined Florida Bay and Florida Keys regions in the south. There, ageostrophic effects occur as the flow field must change direction to navigate the coastline. Friction takes on a larger role relative to the Coriolis term, and advective acceleration effects are also more pronounced. For the Big Bend these findings are consistent with the observations of Marmorino [1983]. Elsewhere, along the Oregon coast, for instance, Allen and Kundu [1978] also show advective acceleration effects to be important. At the shelf break, even in the quasi steady state, the model shows a regular pattern of local acceleration associated with topographic Rossby waves due to stretching of planetary vorticity via cross-isobath flows.
This is consistent with the observations of Niiler [1976], the model results of Hsueh et al. [1982], and the regular appearance in satellite AVHRR images of isotherm perturbations along the shelf break.

A change in the wind stress direction affects the overall shelf response dynamics. The response for the offshore wind-forced case tends to be more ageostrophic relative to the alongshore wind-forced case, although the ordering of terms remains the same, and the Coriolis, pressure gradient, and vertical friction terms are again the most important ones. Unlike the inference from Csanady [1976] that the coastal response to offshore winds should be meager, we find that coastal sea level and coastal jet responses do occur. This again is a consequence of the fully three-dimensional nature of the WFS circulation due to the subtle coastline and isobath geometry variations. Given a coastal jet response to offshore wind stress, the sign of the Coriolis term reverses across the inner shelf to match a classical Ekman response farther offshore.

Since vertical friction is a term of primary importance over 

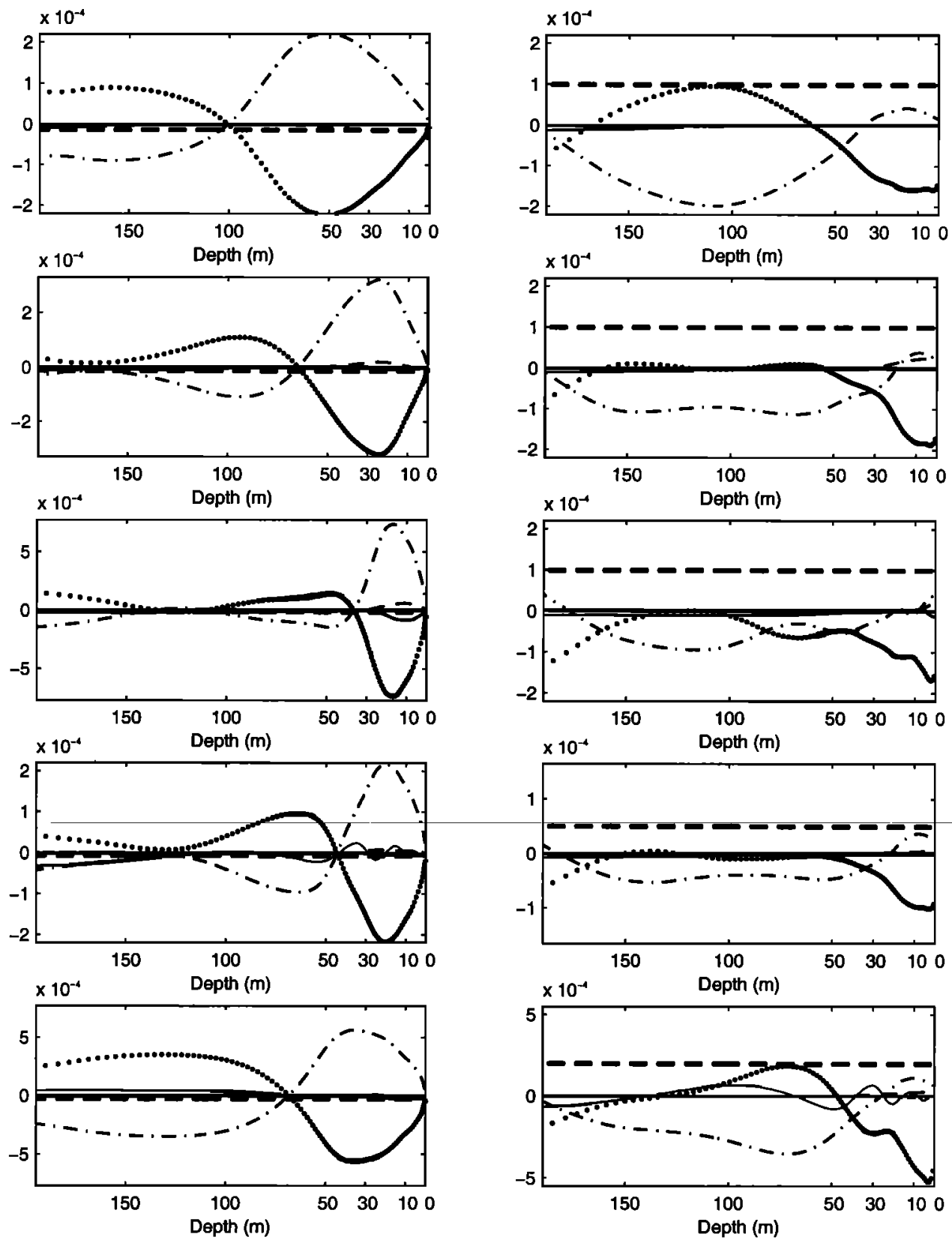

Figure 18. The across-shelf distributions of the depth-integrated momentum terms from the across-shelf momentum equations on day 12 sampled offshore from Sarasota. The left- and right-hand diagrams correspond to the alongshore and the offshore wind cases, respectively. The pressure gradient term is the bold dotted line, the Coriolis term is the dash-dotted line, the wind stress term is the bold dashed line, the bottom stress term is the thin dashed line, the advection term is the bold solid line, and the local acceleration term is the thin solid line. From top to bottom the first three rows result from replacing the default turbulence closure scheme with constant eddy coefficients $K_{m}$ of magnitudes: $5 \times 10^{-2} \mathrm{~m}^{2} \mathrm{~s}^{-1}, 5 \times 10^{-3} \mathrm{~m}^{2} \mathrm{~s}^{-1}$, and $5 \times$ $10^{-4} \mathrm{~m}^{2} \mathrm{~s}^{-1}$, respectively, and the fourth and fifth rows result from retaining the default turbulence closure scheme while changing the forcing magnitude to either $0.5 \mathrm{dyn} \mathrm{cm} \mathrm{cm}^{-2}$ or $2 \mathrm{dyn} \mathrm{cm}^{-2}$, respectively.

the inner shelf, we explore the distribution of the turbulent kinetic energy and the vertical eddy coefficient as derived from the Mellor-Yamada level 2.5 closure submodel used in the POM. Our results are very similar to those of others that have employed this model [e.g., Allen et al., 1995]. The turbulence properties are related to the flow field properties as expected. The response to offshore forcing being more ageostrophic than the response to alongshore forcing is reflected in the turbu- lence property distribution differences between these two experiments.

Testing the sensitivity of the model to different vertical eddy coefficient specifications, we either substituted the default closure submodel with constant eddy coefficients in experiments spanning different orders of magnitude or retained the default closure submodel while varying the wind stress magnitude. In each case the offshore scale of the response varies, which 
further demonstrates that the nature of the inner shelf is determined by the interaction between the surface and bottom Ekman layers. Modulating these layers modulates the inner shelf width and response intensities. Also, despite the three primary terms in the momentum balance being linear (Coriolis, pressure gradient, and vertical friction), the nonlinear default turbulence closure submodel results in responses that are not simply linearly proportional to the forcing amplitude. A modeling challenge will be to determine just how well the turbulence closure submodel represents observations in nature over large ranges of stratification and surface forcing. This point follows the developing findings of others, for example, Weatherly and Martin [1978] and Dickey and Van Leer [1984] for the bottom Ekman layer, Allen et al. [1995] and Lentz [1995] for the water column, and DeSzoeke and Richman [1982] for the surface boundary layer. Lentz and Trowbridge [1991] and Allen and Newberger [1996] also demonstrate that fundamental differences exist between responses to upwelling versus downwelling favorable wind stresses for stratified regions because of differences in the ensuing stability of the bottom Ekman layer.

In summary, we present dynamical analyses of the WFS response to upwelling favorable alongshore or offshore directed wind stresses using a three-dimensional, timedependent primitive equation numerical model with realistic coastline and isobath geometries under a barotropic setting. The momentum balance structures are fully three-dimensional, with the Coriolis, pressure gradient, and vertical friction terms being the most important ones. The inner, middle, and outer shelf regions are dynamically defined. The inner shelf is the region between the coast and the point of classical Ekman balance between the wind stress and the vertically integrated Coriolis force. The inner shelf response rapidly evolves to a quasi steady state for which there exists a surface slope and a coastal jet. Owing to subtle coastline geometry effects giving rise to full three dimensionality, a coastal jet forms for the offshore wind stress case as well as for the alongshore wind stress case. The outer shelf region is that of the shelf break where stretching of planetary vorticity filaments more greatly constrains the across-isobath flow leading to topographic waves. It is also the region where density and pressure effects of the adjacent ocean (not included in this study) are manifest. The middle shelf is the region remaining in between, as modeled for example by Clarke and Van Gorder [1986]. The WFS, unlike many continental shelves, is wide enough to deconvolve these three regions which generally merge into a complicated tangle. The specification of the vertical turbulent eddy coefficient is critical in all three regions. For the inner shelf it modulates the offshore scale and intensity of the coastal jet, and for both the middle and outer shelf it determines acrossshelf buoyancy transports via the Ekman layers and hence the baroclinic structure of these regions. Detailed comparisons between model and observations under varying conditions of stratification and forcing are therefore necessary to determine the degree to which these and other model findings are valid. Obtaining a comprehensive set of measurements is presently underway, and such comparisons will be reported on in the future.
Acknowledgments. Support was from a cooperative agreement between the USGS Center for Coastal Geology, St. Petersburg, Florida, and the University of South Florida and from the U.S. Department of Interior, Minerals Management Service, contract 14-35-0001-30804. The authors benefited from many helpful discussions with $\mathrm{H}$. Yang.

\section{References}

Allen, J. S., and P. K. Kundu, On the momentum, vorticity and mass balance on the Oregon shelf, J. Phys. Oceanogr., 8, 13-27, 1978.

Allen, J. S., and P. A. Newberger, Downwelling circulation on the Oregon continental shelf, I, response to idealized forcing, $J$. Phys. Oceanogr., 26, 2011-2035, 1996.

Allen, J. S., P. A. Newberger, and J. Federiuk, Upwelling circulation on the Oregon continental shelf, I, Response to idealized forcing, $J$. Phys. Oceanogr., 25, 1843-1866, 1995.

Blumberg, A. F., and G. L. Mellor, A description of a threedimensional coastal ocean circulation model, in Three-Dimensional Coastal Ocean Models, Coastal Estuarine Stud., vol. 4, edited by N. Heaps, pp. 208-233, AGU, Washington, D. C., 1987.

Clarke, A. J., and S. Van Gorder, A method for estimating wind-driven frictional, time-dependent stratified shelf and slope water flow, $J$. Phys. Oceanogr., 16, 1013-1028, 1986.

Cooper, C., A numerical modeling study of low-frequency circulation on the west Florida shelf, Coastal Eng., 11, 29-56, 1987.

Csanady, G. T., The arrested topographic wave, J. Phys. Oceanogr., 8, 47-62, 1976.

De Szoeke, R. A., and J. G. Richman, The role of wind-generated mixing in coastal upwelling, J. Phys. Oceanogr., 11, 1534-1547, 1982.

Dickey, T. D., and J. C. Van Leer, Observations and simulation of a bottom Ekman layer on a continental shelf, J. Geophys. Res., 89, 1983-1988, 1984.

Hsueh, Y., G. O. Marmorino, and L. L. Vansant, Numerical model studies of the winter-storm response of the west Florida shelf, $J$. Phys. Oceanogr., 12, 1037-1050, 1982.

Lentz, S. J., Sensitivity of the inner-shelf circulation to the form of the eddy viscosity profile, J. Phys. Oceanogr., 25, 19-28, 1995.

Lentz, S. J., and J. H. Trowbridge, The bottom boundary layer over the northern California shelf, J. Phys. Oceanogr., 21, 1186-1202, 1991.

$\mathrm{Li}, \mathrm{Z}$., and R. H. Weisberg, West Florida continental shelf response to upwelling favorable wind forcing, 1, Kinematics, J. Geophys. Res., 104, 13,507-13,527, 1999.

Marmorino, G. O., Variability of current, temperature, and bottom pressure across the west Florida continental shelf, winter 1981-1982, J. Geophys. Res., 88, 4439-4457, 1983.

Mellor, G. L., and T. Yamada, Development of a turbulence closure model for geophysical fluid problems, Rev. Geophys., 20, 851-875, 1982.

Mitchum, G. T., and A. J. Clarke, The frictional nearshore response to forcing by synoptic scale winds, $J$. Phys. Oceanogr., 16, 934-946, 1986.

Mitchum, G. T., and W. Sturges, Wind-driven currents on the west Florida shelf, J. Phys. Oceanogr., 12, 1310-1317, 1982.

Niiler, P. P., Observations of low-frequency currents on the west Florida continental shelf, Mem. Soc. R. Sci. Liege Collect., 6(X), 331-358, 1976.

Weatherly, G. L., and P. J. Martin, On the structure and dynamics of the oceanic bottom boundary layer, J. Phys. Oceanogr., 8, 557-570, 1978.

Z. Li and R. H. Weisberg, Department of Marine Science, University of South Florida, 140 Seventh Avenue South, St. Petersburg, FL 33701. (l1@marine.usf.edu; weisberg@marine.usf.edu)

(Received December 18, 1998; revised June 14, 1999; accepted June 21, 1999.) 